Board of Governors of the Federal Reserve System

International Finance Discussion Papers

Number 635

April 1999

\title{
OPTIMAL MONETARY POLICY WITH STAGGERED WAGE AND PRICE CONTRACTS
}

Christopher J. Erceg, Dale W. Henderson, Andrew T. Levin

NOTE: International Finance Discussion Papers are preliminary materials circulated to stimulate discussion and critical comment. References in publications to International Finance Discussion Papers (other than an acknowledgment that the writer has had access to unpublished material) should be cleared with the author or authors. Recent IFDPs are available on the Web at www.bog.frb.fed.us. 


\title{
OPTIMAL MONETARY POLICY WITH STAGGERED WAGE AND PRICE CONTRACTS
}

\author{
Christopher J. Erceg, Dale W. Henderson, Andrew T. Levin*
}

\begin{abstract}
We formulate an optimizing-agent model in which both labor and product markets exhibit monopolistic competition and staggered nominal contracts. The unconditional expectation of average household utility can be expressed in terms of the unconditional variances of the output gap, price inflation, and wage inflation. Monetary policy cannot replicate the Pareto-optimal equilibrium that would occur under completely flexible wages and prices; that is, the model exhibits a tradeoff between stabilizing the output gap, price inflation, and wage inflation. The Pareto optimum is only attainable if either wages or prices are completely flexible. For reasonable calibrations of the model, we characterize the optimal policy rule. Furthermore, strict price inflation targeting is clearly suboptimal, whereas rules that place substantial weight on the output gap as well as price inflation are nearly optimal.
\end{abstract}

Keywords: monetary policy, inflation targeting, sticky wages, sticky prices, staggered contracts.

\footnotetext{
*All three authors are economists in the International Finance Division of the Federal Reserve Board. Earlier versions of the paper were presented at the Federal Reserve Board, the Swedish National Bank - Institute for International Economic Studies (IIES) Conference on Monetary Policy Rules, the Meetings of the Western Economic Association, the Federal Reserve Bank of Chicago, and the University of Michigan. The authors would like to thank Stefan Gerlach, their discussant at the Conference, for helpful comments; John Taylor and Michael Woodford for useful discussions; and Carolina Marquez for valuable research assistance. We have benefitted from suggestions made by an anonymous referee and by Robert King. We particularly appreciate the recent contributions of Julio Rotemberg and Michael Woodford, who not only have performed path breaking welfare analysis of monetary policy, but also have developed intuitively appealing explanations of their results and have made substantial efforts to provide the details of their derivations. The views in this paper are solely the responsibility of the authors and should not be interpreted as reflecting the views of the Board of Governors of the Federal Reserve System or of any other person associated with the Federal Reserve System. The email addresses of the authors are ercegc@frb.gov, hendersd@frb.gov, and levina@frb.gov, respectively.
} 


\section{Introduction}

For several decades, economists have investigated the monetary policy tradeoff between price inflation variability and output gap variability, using a wide variety of theoretical and empirical models. ${ }^{1} \quad$ However, the existence of a variance tradeoff has been called into question in recent analysis of dynamic general equilibrium models with optimizing agents, staggered price setting, and completely flexible wages; in these models, monetary policy rules that keep the inflation rate constant also minimize output gap variability. ${ }^{2} \quad$ The monetary authorities can achieve the Pareto-optimal welfare level (that is, the welfare level that would occur in the absence of nominal inertia and monopolistic distortions) through the remarkably simple policy regime of strict price inflation targeting, irrespective of the parameter values or other specific features of these models.

In this paper, we analyze a dynamic general equilibrium model with optimizing agents and staggered wage and price setting. ${ }^{3}$ As in recent contributions, aggregate price inflation induces dispersion in prices and hence inefficient variation in output levels across firms. Similarly, with staggered wage contracts, aggregate wage inflation induces inefficiencies in the distribution of employment across households. Hence, achieving the Pareto-optimal equilibrium would require not only a zero output gap and complete price stability, but also complete stabilization of nominal wages.

These considerations lead directly to our main result: it is impossible for monetary policy to attain the Pareto optimum except in the special cases where either wages or prices are completely flexible. Nominal wages and prices would only remain constant if the aggregate real wage rate were continuously at its Pareto-optimal level, whereas the Pareto-optimal real wage rate moves in response to aggregate productivity and labor supply shocks. Given that the Pareto optimum is infeasible, the monetary policymaker faces tradeoffs in stabilizing wages, prices, and the output gap.

Under staggered wage and price setting, the optimal monetary policy rule depends on the underlying structure and parameter values of the model. These features affect both the set of feasible monetary policy choices (the policy frontier) and the prefer-

\footnotetext{
${ }^{1}$ The seminal papers include Phelps and Taylor (1977), Taylor (1979), and Taylor (1980). Some recent examples include Bryant, Hooper, and Mann (1993); Henderson and McKibbin (1993); Tetlow and von zur Muehlen (1996); Williams (1997); Levin, Wieland, and Williams (1998); Rudebusch and Svensson (1998).

${ }^{2}$ Some of the contributions, such as Goodfriend and King (1997) and King and Wolman (1998), are purely theoretical. Others, such as Ireland (1997), Rotemberg and Woodford (1998b), and Rotemberg and Woodford (1998b), start with theoretical analysis and then simulate models that match certain features of aggregate data.

${ }^{3}$ This model was first presented in Erceg, Henderson, and Levin (1998). Calvo (1983) proposed the timing features of the contracts, and Kimball (1995) and Yun (1996) pioneered the use of price contracts of this type in stochastic, optimizing-agent models. Rotemberg and Woodford (1998b) and Rotemberg and Woodford (1998a) assume that price contracts are of the Calvo type, while King and Wolman (1998) and Goodfriend and King (1997) assume that price contracts are of the Taylor (1980) type. Kollmann (1997), Erceg (1997), and Kim (1999) make assumptions about price and wage determination that are similar to ours. Previous studies in which both prices and wages are sticky include Blanchard and Kiyotaki (1985) the discussion paper version of Blanchard and Kiyotaki (1987) and Solow and Stiglitz (1968).
} 
ences of the policymaker (that is, the indifference loci implied by the policymaker's welfare function). For example, the relative duration of wage and price contracts plays a critical role in determining the optimal monetary policy: we find that the optimal rule induces greater variability in the more flexible nominal variable.

The welfare level under the optimal monetary policy rule provides a natural benchmark against which to measure the performance of alternative policy rules. While strict price inflation targeting is optimal when wages are completely flexible, this monetary regime can induce substantial welfare costs under staggered wage setting. Strict price inflation targeting forces all adjustment in real wages to occur through nominal wage rates, but the latter respond only to the output gap. Thus, compared with the optimal policy rule, such a strategy induces excessive variation in output and nominal wages. We also consider hybrid rules that respond to both price inflation and the output gap, and we find that the performance of such rules is nearly optimal.

This paper is organized as follows. We outline the model in Section 2. In Section 3 , we derive the social welfare function using essentially the same methods employed by Rotemberg and Woodford (1998b). In Section 4, we present key results concerning the policy frontier. We use numerical methods to characterize optimal monetary policy in Section 5, and investigate the welfare costs of alternative policy rules in Section 6. Conclusions and directions for future research are given in Section 7.

\section{The Model}

Our model is similar in many respects to recent optimizing-agent models with nominal price inertia. Intertemporal maximization implies the familiar consumption Euler equation. With monopolistic competition, firms' price-setting behavior is described by a standard equation that links price inflation to the gap between the real wage and the marginal product of labor. In contrast to most recent contributions, we assume that monopolistically competitive households set wages in staggered contracts. Household behavior implies a wage-setting equation that links wage inflation to the gap between the real wage and the marginal rate of substitution of consumption for labor.

Under monopolistic competition, output and labor supply would be below their Pareto-optimal levels in the absence of government intervention, even with perfectly flexible wages and prices. We are convinced that the central task of monetary policy is to mitigate the effects of nominal inertia, while fiscal policy assumes responsibility for offsetting distortions associated with imperfect competition. Therefore, following recent studies, we assume that output and labor are each subsidized at fixed rates to ensure that the equilibrium would be Pareto-optimal if wages and prices were completely flexible. 


\subsection{Firms and Price Setting}

We assume that a continuum of monopolistically competitive firms (indexed on the unit interval) produce differentiated goods that are consumed solely by households. ${ }^{4}$ Because households have identical preferences, it is convenient to abstract from the household's problem of choosing the optimal quantity of each differentiated good $Y_{t}(f)$ for $f \in[0,1]$. Instead, we assume that there is a representative "output aggregator" who combines these goods into a single product that we refer to as the "output index." The output aggregator combines the goods in the same proportions as households would choose, and then sells the output index to households. Thus, the aggregator's demand for each differentiated good is equal to the sum of household demands.

The output index $Y_{t}$ is assembled using a constant returns to scale technology of the Dixit and Stiglitz (1977) form (which mirrors the preferences of households):

$$
Y_{t}=\left[\int_{0}^{1} Y_{t}(f)^{\frac{1}{1+\theta_{p}}} d f\right]^{1+\theta_{p}}
$$

where $\theta_{p}>0$. The output aggregator chooses the bundle of goods that minimizes the cost of producing a given quantity of the output index $Y_{t}$, taking the prices $P_{t}(f)$ of the goods $Y_{t}(f)$ as given. The aggregator sells units of the output index at their unit cost $P_{t}$ :

$$
P_{t}=\left[\int_{0}^{1} P_{t}(f)^{\frac{-1}{\theta_{p}}} d f\right]^{-\theta_{p}}
$$

It is natural to interpret $P_{t}$ as the aggregate price index. The aggregator's demand for each good $Y_{t}(f)$-or equivalently total household demand for this good - is given by

$$
Y_{t}(f)=\left[\frac{P_{t}(f)}{P_{t}}\right]^{\frac{-\left(1+\theta_{p}\right)}{\theta_{p}}} Y_{t}
$$

Each differentiated good is produced by a single firm that hires capital services $K_{t}(f)$ and a labor index $L_{t}(f)$ defined below. Every firm faces the same Cobb-Douglas production function, with an identical level of total factor productivity $X_{t}$ :

$$
Y_{t}(f)=X_{t} K_{t}(f)^{\alpha} L_{t}(f)^{1-\alpha}
$$

The aggregate capital stock is fixed at $\bar{K}$, and capital and labor are perfectly mobile across firms. Each firm chooses $K_{t}(f)$ and $L_{t}(f)$, taking as given the rental price of capital $P_{k, t}$ and the wage index $W_{t}$ defined below. The standard static first-order conditions for cost minimization imply that the firms have identical marginal costs per unit of output $\left(M C_{t}\right)$, which can be expressed as a function of the aggregate

\footnotetext{
${ }^{4}$ Monopolistic competition rationalizes the assumption that firms are willing to satisfy unexpected increases in demand even when they are temporarily constrained not to change their prices.
} 
labor index $L_{t}$, as well as the aggregate capital stock, total factor productivity, and the wage index:

$$
M C_{t}=\frac{W_{t} L_{t}^{\alpha}}{(1-\alpha) \bar{K}^{\alpha} X_{t}}
$$

To introduce nominal price stickiness into the model, we assume that producers set prices in Calvo-style staggered contracts. The duration of each contract is randomly determined: in any given period, the firm is allowed to reset its price contract with probability $\left(1-\xi_{p}\right)$. Whenever the firm is not allowed to reset its contract, the firm's price is automatically increased at the unconditional mean rate of gross inflation, $\Pi$. Thus, if firm $f$ has not adjusted its contract price since period $t$, then its price in period $t+j$ is $P_{t+j}(f)=P_{t}(f) \Pi^{j}$. Note that the probability that a firm will be allowed to reset its contract price in any given period does not depend on how long its existing contract has been in effect, and this probability is invariant to the aggregate state vector. Thus, a constant fraction $\left(1-\xi_{p}\right)$ of firms are allowed to reset their contract prices each period.

When a firm is allowed to reset its price in period $t$, the firm maximizes the following profit functional with respect to its contract price, $P_{t}(f)$ :

$$
\mathcal{E}_{t} \sum_{j=0}^{\infty} \xi_{p}^{j} \psi_{t, t+j}\left(\left(1+\tau_{p}\right) \Pi^{j} P_{t}(f) Y_{t+j}(f)-M C_{t+j} Y_{t+j}(f)\right)
$$

The operator $\mathcal{E}_{t}$ represents the conditional expectation based on information through period $t$ and taken over states of nature in which the firm is not allowed to reset its price. The firm's output is subsidized at a fixed rate $\tau_{p}$. The firm discounts profits received at date $t+j$ by the probability that the firm will not have been allowed to reset its price $\left(\xi_{p}{ }^{j}\right)$ and by the state-contingent discount factor $\psi_{t, t+j}{ }^{5}$

The first-order condition for a price-setting firm is

$$
\mathcal{E}_{t} \sum_{j=0}^{\infty} \xi_{p}^{j} \psi_{t, t+j}\left(\left(1+\tau_{p}\right) \frac{\Pi^{j} P_{t}(f)}{P_{t+j}}-\left(1+\theta_{p}\right) \frac{M C_{t+j}}{P_{t+j}}\right) Y_{t+j}(f)=0
$$

Thus, the firm sets its price so that the sum of its expected discounted real revenue (inclusive of subsidies) is equal to the price markup factor $\left(1+\theta_{p}\right)$ multiplied by the sum of discounted real costs. In the limiting case in which all firms are allowed to set their prices every period $\left(\xi_{p} \rightarrow 0\right)$, equation $(7)$ reduces to the condition (familiar from standard imperfect competition analysis) that the marginal product of labor $\left(M P L_{t}\right)$ multiplied by the subsidy factor $\left(1+\tau_{p}\right)$ equals the real wage multiplied by the price markup factor:

$$
\left(1+\tau_{p}\right) M P L_{t}=\left(1+\theta_{p}\right) \frac{W_{t}}{P_{t}}
$$

\footnotetext{
${ }^{5}$ The discount factor $\psi_{t, t+j}$ is an infinite-dimensional vector with elements corresponding to distinct states of nature in period $t+j$. Each element of $\psi_{t, t+j}$ indicates the price in period $t$ of a claim that pays one dollar if the corresponding state occurs in period $t+j$, divided by the probability that state will occur.
} 


$$
M P L_{t}=(1-\alpha) \bar{K}^{\alpha} L_{t}^{-\alpha} X_{t}
$$

We assume that production is subsidized to eliminate the monopolistic distortion associated with a positive markup. This requires setting $\tau_{p}=\theta_{p}$. Thus, the steady state of the model satisfies the efficiency condition that the marginal product of labor equals the real wage, as in a perfectly competitive economy.

\subsection{Households and Wage Setting}

We assume that a continuum of monopolistically competitive households (indexed on the unit interval) supply differentiated labor services to the production sector; that is, goods-producing firms regard each household's labor services $\mathrm{L}_{t}(h), h \in[0,1]$, as an imperfect substitute for the labor services of other households. It is convenient to assume that a representative labor aggregator (or "employment agency") combines

households' labor hours in the same proportions as firms would choose. Thus, the aggregator's demand for each household's labor is equal to the sum of firms' demands. The labor index $L_{t}$ has the Dixit-Stiglitz form:

$$
L_{t}=\left[\int_{0}^{1} \mathrm{~L}_{t}(h)^{\frac{1}{1+\theta_{w}}} d h\right]^{1+\theta_{w}}
$$

where $\theta_{w}>0$. The aggregator minimizes the cost of producing a given amount of the aggregate labor index, taking each household's wage rate $W_{t}(h)$ as given, and then sells units of the labor index to the production sector at their unit cost $W_{t}$ :

$$
W_{t}=\left[\int_{0}^{1} W_{t}(h)^{\frac{-1}{\theta_{w}}} d h\right]^{-\theta_{w}}
$$

It is natural to interpret $W_{t}$ as the aggregate wage index. The aggregator's demand for the labor hours of household $h$ - or equivalently, the total demand for this household's labor by all goods-producing firms - is given by

$$
\mathrm{L}_{t}(h)=\left[\frac{W_{t}(h)}{W_{t}}\right]^{-\frac{1+\theta_{w}}{\theta_{w}}} L_{t}
$$

The period utility function of household $h$ is separable in three arguments: net consumption, net leisure, and real money balances. Net consumption is defined by subtracting the consumption shock $U_{t}$ from the household's consumption index $C_{t}(h)$. Net leisure is defined by subtracting hours worked $\mathrm{L}_{t}(h)$ and the leisure shock $Z_{t}$ from the household's time endowment (normalized to unity). The consumption and leisure shocks are common to all households. Real money balances are nominal money holdings $M_{t}(h)$ deflated by the aggregate price index $P_{t}$. Thus, the household's period utility function is: 


$$
\begin{aligned}
& \mathbb{U}\left(C_{t}(h), U_{t}\right)+\mathbb{V}\left(\mathrm{L}_{t}(h), Z_{t}\right)+\mu_{0} \mathbb{M}\left(\frac{M_{t}(h)}{P_{t}}\right) \\
= & \frac{\left(C_{t}(h)-U_{t}\right)^{1-\sigma}}{(1-\sigma)}+\frac{\left(1-\mathrm{L}_{t}(h)-Z_{t}\right)^{1-\chi}}{1-\chi}+\frac{\mu_{0}}{(1-\mu)}\left(\frac{M_{t}(h)}{P_{t}}\right)^{1-\mu}
\end{aligned}
$$

Household $h$ 's budget constraint in period $t$ states that consumption expenditures plus asset accumulation must equal disposable income:

$$
\begin{gathered}
P_{t} C_{t}(h)+M_{t}(h)-M_{t-1}(h)+\delta_{t+1, t} B_{t}(h)-B_{t-1}(h) \\
=\left(1+\tau_{w}\right) W_{t}(h) L_{t}(h)+\Gamma_{t}(h)+T_{t}(h)
\end{gathered}
$$

Asset accumulation consists of increases in money holdings and the net acquisition of state-contingent claims. Each element of the infinite-dimensional vector $\delta_{t+1, t}$ represents the price of an asset that will pay one unit of currency in a particular state of nature in the subsequent period, while the corresponding element of the vector $B_{t}(h)$ represents the quantity of such claims purchased by the household. The scalar variable $B_{t-1}(h)$ indicates the value of the household's claims given the current realization of the state of nature. Labor income $W_{t}(h) L_{t}(h)$ is subsidized at a fixed rate $\tau_{w}$. Each household owns an equal share of all firms and of the aggregate capital stock, and receives an aliquot share $\Gamma_{t}(h)$ of aggregate profits and rental income. Finally, each household receives a lump-sum government transfer $T_{t}(h)$. The government's budget is balanced every period, so that total lump-sum transfers are equal to seignorage revenue less output and labor subsidies. ${ }^{6}$

Households set wages in staggered contracts, under assumptions symmetric to those stated earlier for price contracts. In particular, the duration of each wage contract is randomly determined: in any given period, the household is allowed to reset its wage contract with probability $\left(1-\xi_{w}\right)$. Whenever the household is not allowed to reset its wage contract, its wage rate is automatically increased at the unconditional mean rate of gross inflation, $\Pi$. Thus, if household $h$ has not adjusted its wage contract since period $t$, then its wage rate in period $t+j$ is $W_{t+j}(h)=$ $W_{t}(h) \Pi^{j}$. The probability that a household will be allowed to reset its wage contract in a given period does not depend on how long its existing contract has been in effect, and is invariant to the aggregate state vector. Thus, a constant fraction $\left(1-\xi_{w}\right)$ of households are allowed to reset their wage contracts in each period.

In every period $t$, each household $h$ maximizes the following utility functional with respect to its choice of consumption, its holdings of money, and its holdings of contingent claims:

\footnotetext{
${ }^{6}$ Thus, $\Gamma_{t}(h)$ and $T_{t}(h)$ are determined by the following identities:

$$
\begin{gathered}
\int_{0}^{1} \Gamma_{t}(h) d h=\int_{0}^{1}\left[\left(1+\tau_{p}\right) P_{t}(f) Y_{t}(f)-W_{t} \mathrm{~L}_{t}(f)\right] d f \\
M_{t}-M_{t-1}=\int_{0}^{1} \tau_{p} P_{t}(f) Y_{t}(f) d f+\int_{0}^{1} \tau_{w} W_{t} \mathrm{~L}_{t}(h) d h+\int_{0}^{1} T_{t}(h) d h .
\end{gathered}
$$
}




$$
\mathcal{E}_{t} \sum_{j=0}^{\infty} \beta^{j}\left(\mathbb{U}\left(C_{t+j}(h), U_{t}\right)+\mathbb{V}\left(\mathrm{L}_{t+j}(h), Z_{t}\right)+\mathbb{M}\left(\frac{M_{t+j}(h)}{P_{t+j}}\right)\right)
$$

subject to the demand for its labor, equation (12), and its budget constraint, equation (14). The operator $\mathcal{E}_{t}$ here represents the conditional expectation over all states of nature, and the discount factor $\beta$ satisfies $0<\beta<1$.

The first-order conditions for consumption and holdings of state-contingent claims imply the familiar "consumption Euler equation" linking the marginal cost of foregoing a unit of consumption in the current period to the expected marginal benefit in the following period:

$$
\mathbb{U}_{C, t}=\mathcal{E}_{t}\left[\beta\left(1+R_{t}\right) \mathbb{U}_{C, t+1}\right]=\mathcal{E}_{t}\left[\beta\left(1+I_{t}\right) \frac{P_{t}}{P_{t+1}} \mathbb{U}_{C, t+1}\right]
$$

where the risk-free real interest rate $R_{t}$ is the rate of return on an asset that pays one unit of consumption under every state of nature at time $t+1$, and the nominal interest rate $I_{t}$ is the rate of return on an asset that pays one unit of currency under every state of nature at time $t+1$. Note that the omission of the household-specific index for consumption in equation (16) reflects our assumption of complete contingent claims markets for consumption (but not for leisure), which implies that consumption is identical across households in every period $\left(C_{t}(h)=C_{t}\right)$.

In any period $t$ in which household $h$ is able to reset its wage contract, the household also maximizes its utility functional (15) with respect to the wage rate $W_{t}(h)$, yielding the following first-order condition:

$$
\mathcal{E}_{t} \sum_{j=0}^{\infty} \beta^{j} \xi_{w}^{j}\left(\left(1+\tau_{w}\right) \frac{\Pi^{j} W_{t}(h)}{P_{t+j}} \mathbb{U}_{C, t+j}+\left(1+\theta_{w}\right) \mathbb{V}_{\mathrm{L}(h), t+j}\right) \mathrm{L}_{t+j}(h)=0
$$

where $\mathcal{E}_{t}$ here indicates the conditional expectation taken only over states of nature in which the household is unable to reset its wage. In the limiting case in which all households are allowed to set their wages every period $\left(\xi_{w} \rightarrow 0\right)$, equation $(17)$ reduces to the condition that the real wage multiplied by the subsidy factor $\left(1+\tau_{w}\right)$ equals the marginal rate of substitution of labor for consumption $\left(M R S_{t}\right)$ multiplied by the wage markup factor $\left(1+\theta_{w}\right)$ :

$$
\begin{gathered}
\left(1+\tau_{w}\right) \frac{W_{t}}{P_{t}}=\left(1+\theta_{w}\right) M R S_{t} \\
M R S_{t}=-\frac{\mathbb{V}_{\mathrm{L}, t}}{\mathbb{U}_{C, t}}=\frac{\left(C_{t}-U_{t}\right)^{\sigma}}{\left(1-\mathrm{L}_{t}-Z_{t}\right)^{\chi}}
\end{gathered}
$$

We assume that employment is subsidized to eliminate the monopolistic distortion associated with a positive markup. This requires setting $\tau_{w}=\theta_{w}$. Thus, the steady state of the model satisfies the efficiency condition that $M R S_{t}$ equals the real wage, as in a perfectly competitive economy. 


\subsection{The Steady State}

The non-stochastic steady state of our model is derived by setting the three shocks to their mean values $(\bar{U}, \bar{X}$, and $\bar{Z})$. Given that both wage and price contracts are indexed to the steady-state inflation rate $\Pi$, the steady state is the same as if wages and prices were fully flexible. Thus, the steady state is Pareto-optimal, with all firms producing the same amount of output $(\bar{Y}(f)=\bar{Y})$, and all households supplying the same quantity of labor hours $(\bar{L}(f)=\bar{L})$, where variables with bars represent steady-state values. Using the production function (4) to determine labor hours in terms of output, equilibrium values of the real wage and output are determined by the intersection of the representative firm's $M P L_{t}$ schedule (8), and the representative household's $M R S_{t}$ schedule (18), using the definitions of $M P L_{t}$ and $M R S_{t}$ given in equations (9) and (19), respectively. The real interest rate $\bar{R}$ is determined by the consumption Euler equation (16). ${ }^{7}$

\subsection{The Pareto Optimum}

For comparative purposes, we consider the equilibrium of our model under flexible prices and wages, henceforth referred to as the Pareto optimum. We follow the standard approach of log-linearizing around the steady state of our model to study its approximate dynamics. Small letters denote the deviations of logarithms of the corresponding variables from their steady state levels, and letters with asterisk superscripts represent Pareto-optimal values of the corresponding variables. We solve for values of Pareto-optimal output $\left(y_{t}^{*}\right)$, the real wage $\left(\zeta_{t}^{*}\right)$, and real interest rate $\left(r_{t}^{*}\right)$ using the same equations as used above to obtain the steady state:

$$
\begin{gathered}
y_{t}^{*}=\frac{(1-\alpha) \sigma \bar{\ell}_{U}}{\Lambda} u_{t}-\frac{(1-\alpha) \chi \bar{\ell}_{Z}}{\Lambda} z_{t}+\frac{\left(1+\chi \bar{\ell}_{\mathrm{L}}\right)}{\Lambda} x_{t} \\
\zeta_{t}^{*}=\frac{-\alpha \sigma \bar{\ell}_{U}}{\Lambda} u_{t}+\frac{\alpha \chi \bar{\ell}_{\mathrm{L}}}{\Lambda} z_{t}+\frac{\chi \ell_{L}+\alpha \bar{\ell}_{C}}{\Lambda} x_{t} \\
r_{t}^{*}=\sigma \bar{\ell}_{C}\left(y_{t+1 \mid t}^{*}-y_{t}^{*}\right)+\sigma \bar{\ell}_{U}\left(u_{t+1 \mid t}-u_{t}\right) \\
\Lambda=\alpha+\chi \bar{\ell}_{\mathrm{L}}+(1-\alpha) \sigma \bar{\ell}_{C}
\end{gathered}
$$

where

$$
\bar{\ell}_{C}=\frac{\bar{C}}{(\bar{C}-\bar{U})}, \quad \bar{\ell}_{U}=\frac{\bar{U}}{(\bar{C}-\bar{U})}, \quad \bar{\ell}_{\mathbf{L}}=\frac{\overline{\mathbf{L}}}{(1-\overline{\mathbf{L}}-\bar{Z})}, \quad \bar{\ell}_{Z}=\frac{\bar{Z}}{(1-\overline{\mathbf{L}}-\bar{Z})} .
$$

The subscript $t+1 \mid t$ indicates a one-step-ahead forecast of the variable based on information available through period $t$.

A positive consumption shock raises the marginal utility of a given level of the consumption index, inducing an increase in labor supply that raises $y_{t}^{*}$ and reduces

\footnotetext{
${ }^{7}$ We set $\bar{U}=0.3163, \bar{X}=4.0266, \bar{Z}=0.03$, and $\bar{K}=30 \bar{U}$. Using the baseline calibration described in Section 5.1 (namely, $\alpha=0.3$, and $\sigma=\chi=1.5$ ), we obtain $\bar{L}=0.27$ and $\bar{Y}=10 \bar{U}=$ 3.163. Thus, $\bar{L}$ and $\bar{Z}$ together account for about one-third of the household's time endowment, and the steady state capital/output ration is equal to 3 .
} 
$\zeta_{t}^{*}$. A positive leisure shock reduces labor supply by raising the marginal disutility of a given amount of labor hours, thereby decreasing $y_{t}^{*}$ and increasing $\zeta_{t}^{*}$. Finally, the productivity shock $x_{t}$ increases labor demand and labor supply, and raises both $y_{t}^{*}$ and $\zeta_{t}^{*}$.

\subsection{The Dynamic Equilibrium}

With staggered wage and price setting, the key equations of the model are listed in Table 1. Given that output can deviate from its Pareto-optimal value, we define the output gap $g_{t}=y_{t}-y_{t}^{*}$.

In the consumption Euler equation (T1.1), the expected change in the output gap depends on the deviation of the short-term real interest rate (that is, the nominal interest rate $i_{t}$ less expected output price inflation $\pi_{t+1 \mid t}$ ) from the equilibrium real interest rate $r_{t}^{*}$. Solving the equation forward, the current output gap depends negatively on an unweighted sum of current and future short-term real interest rates, naturally interpreted as the "long-term" real interest rate. This equation resembles a Keynesian IS curve (abstracting from the restrictions it places on the shock process). ${ }^{8}$

Equations (T1.2) and (T1.3) are simple transformations of the $M P L_{t}$ and $M R S_{t}$ equations (9) and (19), respectively. The marginal product of labor, $m p l_{t}$, is inversely related to the output gap, while the marginal rate of substitution, $m r s_{t}$, is positively related to the output gap. The output gap is zero at the intersection of the $m p l_{t}$ and $m r s_{t}$ schedules, namely, at the Pareto-optimal real wage rate, $\zeta_{t}^{*}$.

\begin{tabular}{|clc|}
\hline \multicolumn{1}{|c}{ Table 1: Key Equations } & \\
$g_{t}=g_{t+1 \mid t}-\frac{1}{\sigma \bar{\ell}_{C}}\left(i_{t}-\pi_{t+1 \mid t}-r_{t}^{*}\right)$ & (goods demand) & $(T 1.1)$ \\
$m p l_{t}=\zeta_{t}^{*}-\frac{\alpha}{1-\alpha} g_{t}$ & (marginal product of labor) & $(T 1.2)$ \\
$m r s_{t}=\zeta_{t}^{*}+\left(\frac{\chi \bar{\ell}_{\mathrm{L}}}{1-\alpha}+\sigma \bar{\ell}_{C}\right) g_{t}$ & (marginal rate of substitution) & $(T 1.3)$ \\
$\pi_{t}=\beta \pi_{t+1 \mid t}+\kappa_{p}\left(\zeta_{t}-m p l_{t}\right)$ & (price setting) \\
where $\kappa_{p}=\frac{\left(1-\xi_{p} \beta\right)\left(1-\xi_{p}\right)}{\xi_{p}}$ & & $(T 1.4)$ \\
$\omega_{t}=\beta \omega_{t+1 \mid t}+\kappa_{w}\left(m r s_{t}-\zeta_{t}\right)$ & (wage setting) \\
where $\kappa_{w}=\frac{\left(1-\xi_{w} \beta\right)\left(1-\xi_{w}\right)}{\xi_{w}\left(1+\chi \bar{\ell}_{\mathrm{L}}\left(\frac{1+\theta_{w}}{\theta_{w}}\right)\right)}$ & & $(T 1.5)$ \\
$\zeta_{t}=\zeta_{t-1}+\omega_{t}-\pi_{t}$ & & \\
\hline
\end{tabular}

\footnotetext{
${ }^{8}$ See, for example, Woodford (1996) and Kerr and King (1996).
} 
The price-setting equation (T1.4) is derived from the first-order condition of the firm for setting its contract price (7). ${ }^{9}$ Current price inflation (as a deviation from steady state) depends positively both on expected price inflation and on the percentage by which the real wage, $\zeta_{t}$, exceeds the marginal product of labor, $m p l_{t}$. Solving the equation forward reveals that price inflation depends on current and expected future gaps between real wages and marginal products of labor. Thus, price inflation only equals its steady state level when firms are operating on their labor demand schedules and expect to continue doing so. Otherwise, there is a non-degenerate distribution of output prices across firms, and $m p l_{t}-\zeta_{t}$ should be interpreted as the average across firms. Using equations (5), (8) and (9), it is evident that the pricemarginal cost markup can be expressed as the ratio of the marginal product of labor to the real wage:

$$
\frac{P_{t}}{M C_{t}}=\frac{M P L_{t}}{\frac{W_{t}}{P_{t}}}
$$

It follows that the price-setting equation (T1.4) can be expressed in an equivalent form that has appeared frequently in the literature: price inflation depends on the percentage deviation of the price-marginal cost markup from its constant desired level of unity. ${ }^{10}$

As shown in Appendix A, the wage-setting equation (T1.5) is derived from the first-order condition of the household for setting its contract wage rate (17). This equation states that the amount by which current wage inflation exceeds its steadystate value $(\Pi)$ depends on the percentage by which households' average marginal rate of substitution, $m r s_{t}$, exceeds the real wage, taking expected wage inflation next period as given. Wage inflation only equals its steady-state level when households operate on and expect to continue to operate on their labor supply schedules. Otherwise, there is a non-degenerate distribution of wage rates and leisure hours across households, and $m r s_{t}-\zeta_{t}$ should be interpreted as the average across all households. The wage-setting equation, like the price-setting equation, can be expressed equivalently in terms of the wage markup, namely, the percentage deviation of the real wage from the $m r s_{t}$ of households.

The identity (T1.6) expresses the change in the real wage as the difference between wage inflation and price inflation. Finally, a monetary policy rule is required to close the model. Such a rule is not listed in Table 1, but in Section 5 we will consider feedback rules in which the short-term nominal interest rate $i_{t}$ (expressed as a deviation from its steady-state value) responds linearly to some or all of the endogenous variables and exogenous disturbances.

It is interesting to note that the model in Table 1 has some formal similarity to the earlier work on "disequilibrium" models. ${ }^{11}$ In particular, wages and prices are

\footnotetext{
${ }^{9}$ The derivation is virtually identical to the one in Yun (1996) and is very similar to the derivation of the wage-setting equation given in Appendix A. A very similar price-setting equation is implied by the assumption of quadratic menu costs of adjusting nominal prices as shown by Rotemberg (1996).

${ }^{10} \mathrm{See}$, for example, the studies cited in footnote 2.

${ }^{11}$ Earlier work on disequilibrium models by Clower, Patinkin, Barro and Grossman, Benassy, Grandmont, Henin, Malinvaud, Negishi, Portes and others is cited in Quandt (1987)
} 
subject to nominal inertia and exhibit partial adjustment toward the Pareto-optimal equilibrium. However, the wage and price equations in Table 1 are derived from optimizing behavior, and thus depend on the underlying structure of preferences and technology as well as exogenously-specified mean contract duration parameters.

\section{The Welfare Function}

Following recent contributions, we assume that the monetary policymaker maximizes the unconditional expectation of the unweighted average of household utility functionals. $^{12}$ This problem is equivalent to maximizing the unconditional expectation of the average of household period utility functions, $\mathbb{W}_{t}$, referred to hereafter as the policymaker's period welfare function. ${ }^{13}$

$$
\mathbb{W}_{t}=\mathbb{U}\left(C_{t}, U_{t}\right)+\int_{0}^{1} \mathbb{V}\left(\mathrm{L}_{t}(h), Z_{t}\right) d h .
$$

In this expression, consumption is identical across households whereas labor hours may vary across households (due to complete contingent claims for consumption but not for leisure). In addition, this expression for $\mathbb{W}_{t}$ reflects our assumption that the welfare losses related to fluctuations in real balances are sufficiently small to be ignored. ${ }^{14}$ The Pareto-optimal period welfare function is given by $\mathbb{W}_{t}^{*}=\mathbb{U}\left(C_{t}^{*}, U_{t}\right)+$ $\mathbb{V}\left(\mathrm{L}_{t}^{*}, Z_{t}\right)$.

\subsection{Approximation of the Period Welfare Function}

To analyze the deviation of the policymaker's period welfare from the Pareto optimum, we derive the second-order Taylor approximations of $\mathbb{W}_{t}$ and $\mathbb{W}_{t}^{*}$ around the steady-state period welfare level $\overline{\mathbb{W}}$, and take their difference: ${ }^{15}$

$$
\begin{aligned}
\mathbb{W}_{t}-\mathbb{W}_{t}^{*}= & -\frac{1}{2} \mathbb{U}_{C}(\bar{C}, \bar{U}) \bar{C}\left(\frac{\alpha}{1-\alpha}+\sigma \bar{\ell}_{C}+\frac{\chi \bar{\ell}_{L}}{1-\alpha}\right) g_{t}^{2}+\left.\frac{1}{2} \mathbb{V}_{L L}(\bar{L}, \bar{Z}) \bar{L}^{2} \operatorname{var}_{h}\right|_{t}(h) \\
& +\frac{1}{2} \mathbb{V}_{L}(\bar{L}, \bar{Z}) \bar{L}\left(\left.\frac{\theta_{w}}{1+\theta_{w}} \operatorname{var}_{h}\right|_{t}(h)+\frac{1}{1-\alpha} \frac{\theta_{p}}{1+\theta_{p}} \operatorname{var}_{f} y_{t}(f)\right)
\end{aligned}
$$

where $\mathrm{I}_{t}(h)$ indicates the percent deviation from steady state of the labor hours $\mathrm{L}_{t}(h)$ of household $h$, and $\operatorname{var}_{h} \mathrm{I}_{t}(h)$ indicates the cross-sectional dispersion of $\mathrm{I}_{t}(h)$. Similarly, $y_{t}(f)$ indicates the percent deviation from steady state of the output $Y_{t}(f)$ of firm $f$, and $\operatorname{var}_{f} y_{t}(f)$ indicates the cross-sectional dispersion of $y_{t}(f) .{ }^{16}$

\footnotetext{
${ }^{12}$ Examples include studies cited in footnote 2 and Rudebusch and Svensson (1998).

${ }^{13}$ This equivalence follows from $\mathcal{E} \sum_{j=0}^{\infty} \beta^{j} \mathbb{W}_{t+j}=\left(\frac{1}{1-\beta}\right) \mathcal{E}\left(\mathbb{W}_{t}\right)$.

${ }^{14}$ That is, we assume that the weight $\mu_{0}$ in equation (13) is arbitrarily close to zero.

${ }^{15}$ This expression is the same as equation $(B .16)$ which is derived in Appendix B since our model implies $\mathbb{V}_{\mathrm{L}} \overline{\mathrm{L}}=-\mathbb{U}_{C} \bar{C}(1-\alpha)$ and $\mathbb{V}_{\mathrm{LL}} \overline{\mathrm{L}}^{2}=-\mathbb{U}_{C} \bar{C}(1-\alpha) \chi \ell_{\mathrm{L}}$.

${ }^{16}$ That is, $\operatorname{var}_{h} \mathbf{I}_{t}(h)=\int_{0}^{1}\left(\mathbf{I}_{t}(h)-E_{h} \mathbf{l}_{t}(h)\right)^{2} d h$ and $\operatorname{var}_{f} y_{t}(f)=\int_{0}^{1}\left(y_{t}(f)-E_{f} y_{t}(f)\right)^{2} d f$, where $E_{h} \mathbf{l}_{t}(h)=\int_{0}^{1} \mathbf{I}_{t}(h) d h$ and $E_{f} y_{t}(f)=\int_{0}^{1} y_{t}(f) d f$.
} 
Note that the marginal utility of work is negative $\left(\mathbb{V}_{L}(\bar{L}, \bar{Z})<0\right)$ and decreasing $\left(\mathbb{V}_{L L}(\bar{L}, \bar{Z})<0\right)$, so that the all three terms on the right hand side of equation $(24)$ are negative.

The first term captures the period welfare cost of variation in the output gap. This welfare cost is incurred with both synchronized and staggered nominal contracts and even in the absence of nominal inertia. For a given output gap $g_{t}$, Figure 1 depicts this welfare cost (as a percentage of steady state output) as the shaded area between the upward-sloping $m r s_{t}$ schedule (equation (T1.3)) and the downward-sloping $m p l_{t}$ schedule (equation $(T 1.5))^{17}$ Since $\sigma \bar{\ell}_{C}+\frac{\chi \bar{\ell}_{L}}{1-\alpha}$ is the slope of the $m r s_{t}$ schedule and $\frac{\alpha}{1-\alpha}$ is the slope of the $m p l_{t}$ schedule, the shaded area is given by $\frac{1}{2}\left(\sigma \bar{\ell}_{C}+\frac{\chi \bar{\ell}_{L}}{1-\alpha}+\frac{\alpha}{1-\alpha}\right) g_{t}^{2}$. Thus, the welfare cost of a given output gap increases with the steepness of the $m r s_{t}$ and $m p l_{t}$ schedules. Multiplying the shaded area by $\mathbb{U}_{C}(\bar{C}, \bar{U}) \bar{C}$ gives the period welfare cost in terms of utility.

The remaining two terms capture the period welfare costs of cross-sectional dispersion that arise only when price and wage setting are staggered. Even when the output gap is zero, staggered wage setting leads to dispersion in hours worked across households, while staggered price setting leads to dispersion in differentiated goods production across firms. Cross-sectional dispersion in hours imposes a welfare cost (captured by the second term) because households dislike variation in their labor supply, that is, because households have decreasing marginal utility of work $\left(\mathbb{V}_{L L}(\bar{L}, \bar{Z})<0\right)$.

In addition, both cross-sectional dispersion in hours and cross-sectional dispersion in outputs impose inefficiencies (captured by the third term) by raising the aggregate labor hours, $\mathrm{L}_{t}=\int_{0}^{1} \mathrm{~L}_{t}(h) d h$, needed to produce a given level of the output index. These inefficiencies would arise even if the marginal utility of leisure were constant $\left(\mathbb{V}_{L L}(\bar{L}, \bar{Z})=0\right) .{ }^{18} \quad$ Labor services of households are imperfect substitutes in production, and differentiated goods are imperfect substitutes in consumption; thus, the magnitudes of the inefficiencies increase with the degrees of concavity of the labor index and of the output index (as determined by the values of the wage markup rate $\theta_{w}$ and the price markup rate $\left.\theta_{p}\right)$. Since each household's labor hours enter symmetrically into the aggregate labor index, and every household has equal weight in the social welfare function, the Pareto-optimal equilibrium has the property that the number of labor hours is identical across households. Under staggered wage setting, however, the economy no longer exhibits this optimality property. The inefficiency associated with cross-sectional dispersion of labor hours can be expressed in terms of the percentage increase in aggregate labor hours required to produce a given level of the labor index:

${ }^{17}$ This graphical representation is used in Blanchard and Kiyotaki (1985) and Aizenman and Frenkel (1986) which apparently contains the first proof that the welfare cost of variations in the output gap can be represented by a loss in economic surplus.

${ }^{18}$ As a second-order approximation, equation (24) omits higher-order terms that involve the interaction between productive inefficiencies and aggregate output fluctuations, as well as higher-order terms associated with the response of leisure dispersion to fluctuations in the work hours of the average household. 


$$
\mathrm{I}_{t}=l_{t}+\frac{1}{2}\left(\frac{\theta_{w}}{1+\theta_{w}}\right) \operatorname{var}_{h} \mathrm{I}_{t}(h)
$$

where $I_{t}$ is the percent deviation from steady state of average labor hours, $\mathrm{L}_{t}$, and $l_{t}$ is the percent deviation from steady state of the labor index, $L_{t}$.

Similarly, staggered price setting induces cross-sectional dispersion in production, and thereby increases the average level of differentiated goods output required to produce a given level of the output index. Since all firms face the same Cobb-Douglas production function (equation (4)), this inefficiency can be expressed in terms of the percentage increase in the labor index required to produce a given level of the output index:

$$
l_{t}=\frac{1}{(1-\alpha)}\left[y_{t}-x_{t}+\frac{1}{2}\left(\frac{\theta_{p}}{1+\theta_{p}}\right) \operatorname{var}_{f} y_{t}(f)\right]
$$

where $y_{t}$ and $x_{t}$ are the percent deviations from steady state of the output index $Y_{t}$ and of total factor productivity $X_{t}$, respectively.

Substitution of equation (26) into equation (25) yields the following expression:

$$
\mathrm{I}_{t}=\left(\frac{1}{1-\alpha}\right)\left(y_{t}-x_{t}\right)+\frac{1}{2}\left(\frac{\theta_{w}}{1+\theta_{w}}\right) \operatorname{var}_{h} \mathrm{I}_{t}(h)+\frac{1}{2}\left(\frac{1}{1-\alpha}\right)\left(\frac{\theta_{p}}{1+\theta_{p}}\right) \operatorname{var}_{f} y_{t}(f) .
$$

The first term on the right hand side of equation (27) represents the amount of labor hours that would be needed even in the absence of any cross-sectional dispersion. Multiplying the final two terms by $\mathbb{V}_{L}(\bar{L}, \bar{Z}) \bar{L}$ gives the period welfare costs of these inefficiencies, as indicated by the third term in equation (24).

\subsection{Welfare Cost of Aggregate Volatility}

The policymaker's objective is to maximize the unconditional expectation of equation (24). The resulting equation can be expressed in terms of the unconditional variances of the output gap, price inflation, and wage inflation. We begin by noting that the demand function faced by differentiated-goods producers (equation (3)) directly implies that:

$$
\operatorname{var}_{f} y_{t}(f)=\left(\frac{1+\theta_{p}}{\theta_{p}}\right)^{2} \operatorname{var}_{f} p_{t}(f)
$$

Thus, cross-sectional output dispersion varies directly with price dispersion, with the former tending toward infinity as goods become closer to perfect substitutes (that is, as the price markup rate $\theta_{p}$ approaches zero). Moreover, Appendix B demonstrates that:

$$
\mathcal{E}\left[\operatorname{var}_{f} p_{t}(f)\right]=\left(\frac{\xi_{p}}{\left(1-\xi_{p}\right)^{2}}\right) \mathcal{V} a r\left(\pi_{t}\right)
$$

where the operator $\mathcal{V}$ ar indicates the unconditional variance. Thus, cross-sectional price dispersion associated with a given variance of price inflation increases with the average duration of price contracts. Combining equations (28) and (29) yields an 
expression for $\mathcal{E}\left[\operatorname{var}_{f} y_{t}(f)\right]$ in terms of $\mathcal{V} a r\left(\pi_{t}\right)$. Analogous relationships yield a similar expression for $\mathcal{E}\left[\operatorname{var}_{h} \mathrm{l}_{t}(h)\right]$ in terms of $\mathcal{V} a r\left(\omega_{t}\right)$.

Thus, the expected deviation of social welfare from its Pareto-optimal level can be expressed as follows:

$$
\begin{aligned}
\frac{\mathcal{E}\left[\mathbb{W}-\mathbb{W}^{*}\right]}{\mathbb{U}_{C}(\bar{C}, \bar{U}) \bar{C}}= & -\frac{1}{2}\left(\frac{\alpha}{1-\alpha}+\sigma \bar{\ell}_{C}+\frac{\chi \bar{\ell}_{L}}{1-\alpha}\right) \mathcal{V} a r\left(g_{t}\right) \\
& -\frac{1}{2}\left(\frac{1+\theta_{p}}{\theta_{p}}\right)\left(\frac{1-\beta \xi_{p}}{1-\xi_{p}}\right) \frac{1}{\kappa_{p}} \mathcal{V} a r\left(\pi_{t}\right)-\frac{1}{2}\left(\frac{1+\theta_{w}}{\theta_{w}}\right)\left(\frac{1-\beta \xi_{w}}{1-\xi_{w}}\right) \frac{1-\alpha}{\kappa_{w}} \mathcal{V} a r\left(\omega_{t}\right)
\end{aligned}
$$

where the price and wage adjustment coefficients $\kappa_{p}$ and $\kappa_{w}$ are defined in Table 1 above. The welfare deviation from the Pareto-optimal level is scaled by $\mathbb{U}_{C}(\bar{C}, \bar{U}) \bar{C}$, so that the right-hand side of equation (30) represents these welfare losses as a fraction of steady state-consumption.

Several important qualitative features of the social welfare function are evident from equation (30). The welfare cost of price inflation volatility increases with the degree of substitutability across differentiated goods (which is inversely related to the price markup rate $\theta_{p}$ ) and with the mean duration of price contracts (which varies positively with $\xi_{p}$ and negatively with $\left.\kappa_{p}\right) .{ }^{19}$ Welfare is independent of the variance of price inflation only in the special case of completely flexible prices (that is, $\xi_{p}=0$ and hence $\left.\kappa_{p}=\infty\right)$. Similarly, the welfare cost of wage inflation volatility increases with the degree of substitutability across differentiated labor inputs (which is inversely related to the wage markup rate $\theta_{w}$ ) and with the mean duration of wage contracts (which varies positively with $\xi_{w}$ and negatively with $\kappa_{w}$ ). If wages and prices have identical markup rates $\left(\theta_{p}=\theta_{w}\right)$ and identical mean contract duration $\left(\xi_{p}=\xi_{w}\right)$, then the costs of wage inflation volatility exceed those of price inflation volatility for reasonable values of $\alpha$, because the wage adjustment coefficient $\kappa_{w}$ is smaller than the price adjustment coefficient $\kappa_{p}$. Finally, it should be noted that the welfare cost of output gap volatility does not depend on either $\xi_{p}$ or $\xi_{w}$. Thus, the relative weight on output gap volatility declines with the mean duration of price contracts and the mean duration of wage contracts.

\section{The Policy Frontier}

We have shown that the policymaker's welfare function can be expressed in terms of the variances of three aggregate variables: the output gap, price inflation, and wage inflation. Now we demonstrate the impossibility of completely stabilizing more than one of these three variables, using the aggregate supply relations (T1.2) through (T1.5). Therefore, monetary policy cannot achieve the Pareto-optimal level of social welfare. Instead, the policymaker faces tradeoffs in stabilizing the three variables; these tradeoffs are summarized by the policy frontier. The Pareto optimum can be

\footnotetext{
${ }^{19}$ It is important to note that our log-linear approximation becomes relatively inaccurate as the degree of substitutability of differentiated goods or labor services approaches infinity, that is, as either $\theta_{p}$ or $\theta_{w}$ approach zero.
} 
achieved only in the two special cases in which either prices or wages are completely flexible. ${ }^{20}$

\subsection{The General Case}

Our result for the general case of staggered wage and price setting is stated in the following proposition:

Proposition 1: With staggered wage and price setting $\left(\xi_{w}>0\right.$ and $\left.\xi_{p}>0\right)$,

(A) There exists a tradeoff between stabilizing the output gap, the price inflation rate, and the wage inflation rate: it is impossible for more than one of the three variables $g_{t}, \pi_{t}$, and $\omega_{t}$ to have zero variance.

(B) Monetary policy cannot achieve the Pareto-optimal level of social welfare.

The proof of Part (A) is based on the supply relations (T.1.2) through (T.1.5). In particular, it is evident from equation (T1.4) that price inflation remains constant if and only if all firms are continuously on their labor demand schedules (that is, $\pi_{t}=\pi_{t+1 \mid t}=0$ if and only if $\zeta_{t}=m p l_{t}$ ). Similarly, from equation (T1.5), wage inflation remains constant if and only if all households are continuously on their labor supply schedules (that is, $\omega_{t}=\omega_{t+1 \mid t}=0$ if and only if $\zeta_{t}=m r s_{t}$ ). From equations (T1.2) and (T1.3), the Pareto-optimal values of the output index and real wage rate occur at the intersection of the labor supply and labor demand schedules; that is, if $\zeta_{t}=m p l_{t}=m r s_{t}$, then $g_{t}=0$ and $\zeta_{t}=\zeta_{t}^{*}$. Thus, any two of the three conditions $\left(g_{t}=0, \zeta_{t}=m p l_{t}\right.$, and $\left.\zeta_{t}=m r s_{t}\right)$ imply the third condition. As evident in equation (20), the Pareto-optimal real wage $\zeta_{t}^{*}$ moves in response to each of the exogenous shocks; however, the actual real wage $\zeta_{t}$ would always remain at its steady-state value if neither prices nor wages ever adjust. Given this contradiction, it follows that no more than one of the three variables $g_{t}, \pi_{t}$, and $\omega_{t}$ can have zero variance when the exogenous shocks have non-zero variance.

The contradiction is illustrated in Figure 1. Point $A$ represents an initial Paretooptimal equilibrium. Point $B$ represents the Pareto-optimal equilibrium following a positive productivity shock. ${ }^{21}$ Assuming that any two of the three variables $g_{t}, \pi_{t}$, and $\omega_{t}$ are completely stabilized implies that the economy must be at both point $A$ and point $B$, which is impossible.

Part (B) follows immediately from Part (A) and the fact that with staggered wage and price setting all three variables enter the policymaker's welfare function with weights that are strictly negative.

\footnotetext{
${ }^{20}$ The results in this section were first established in Erceg, Henderson, and Levin (1998).

${ }^{21}$ According to equations (T1.3) and (T1.5) any shock shifts both schedules vertically by the amount of the change in the equilibrium real wage. We consider a positive productivity shock as an example.
} 


\subsection{Two Special Cases}

As noted in the introduction, recent studies have characterized optimal monetary policy in optimizing-agent models in which sticky prices are the sole source of nominal rigidity. The salient findings of these studies is that monetary policy faces no tradeoff between minimizing variability in the output gap and minimizing variability in price inflation, so that it can achieve the Pareto optimal welfare level. These findings are consistent with the implications of the special case of our model in which wages are completely flexible:

Proposition 2:

(A) With completely flexible wages $\left(\xi_{w}=0\right)$, it is possible to completely stabilize price inflation and the output gap; with completely flexible prices $\left(\xi_{p}=0\right)$, it is possible to completely stabilize wage inflation and the output gap.

(B) If either wages or prices are completely flexible, monetary policy can achieve the Pareto-optimal level of social welfare.

To prove Part (A) for completely flexible wages, note that zero variance of price inflation implies that firms are always on their labor demand schedules $\left(\zeta_{t}=m p l_{t}\right)$. In this case, however, nominal wages adjust freely to keep households on their labor supply schedules; that is, when $\xi_{w}=0$, the condition $\zeta_{t}=m r s_{t}$ does not imply that nominal wage inflation remains constant. Thus, the condition $\zeta_{t}=m r s_{t}$ can be combined with equations $(T 1.2),(T 1.3)$, and (T1.4) to obtain a relatively familiar expectational Phillips curve, except for the absence of an error term:

$$
\pi_{t}=\beta \pi_{t+1 \mid t}+\left(\frac{\kappa_{p} \Lambda}{1-\alpha}\right) g_{t}
$$

It can be seen from this equation that if price inflation is completely stabilized $\left(\pi_{t}=\right.$ $\left.\pi_{t+1 \mid t}=0\right)$, then the output gap also has zero variance in this special case. Solving equation (31) forward, it is also evident that stabilizing the output gap stabilizes price inflation.

Alternatively, when wages are sticky but prices are completely flexible $\left(\xi_{w}>0\right.$ and $\left.\xi_{p}=0\right)$, prices adjust freely to keep firms on their labor demand schedules. Thus, the condition $\zeta_{t}=m p l_{t}$ can be combined with equations $(T 1.2),(T 1.3)$, and $(T 1.5)$ to obtain the following wage-setting relation:

$$
\omega_{t}=\beta \omega_{t+1 \mid t}+\left(\frac{\kappa_{w} \Lambda}{1-\alpha}\right) g_{t}
$$

Comparison with equation (31) reveals the formal symmetry between the two special cases. In this case, complete wage inflation stabilization $\left(\omega_{t}=\omega_{t+1 \mid t}=0\right)$ stabilizes the output gap, while prices adjust freely to keep the real wage at its Pareto-optimal value.

Part (B) follows immediately from Part (A) and the facts that with completely flexible wages the variance of wage inflation does not enter the policymaker's welfare function and that with perfectly flexible prices the variance of price inflation does not enter the policymaker's welfare function. 


\subsection{Comparison with Existing Literature}

With completely flexible wages, Proposition 2 indicates that staggered price setting by itself does not imply a price inflation-output gap variance tradeoff. To obtain such a tradeoff, one approach taken in the existing literature has been to add an exogenous shock $\phi_{t}$ to equation (31):

$$
\pi_{t}=\beta \pi_{t+1 \mid t}+\lambda_{p} g_{t}+\phi_{t}
$$

Such a shock does in fact arise as an estimation residual, and has been viewed as representing aggregate pricing mistakes or other unexplained deviations from the optimality condition (31). In this case, if price inflation is completely stabilized, then the variance of the output gap is proportional to the variance of the exogenous shock.

In contrast, a price inflation-output gap variance tradeoff arises endogenously in our model with staggered wage and price setting. By substituting the $m p l_{t}$ schedule (T1.2) into the price-setting equation (T1.4), we obtain the following relationship:

$$
\pi_{t}=\beta \pi_{t+1 \mid t}+\kappa_{p}\left(\frac{\alpha}{1-\alpha}\right) g_{t}+\kappa_{p}\left(\zeta_{t}-\zeta_{t}^{*}\right)
$$

Under complete price inflation stabilization, the variance of the output gap is proportional to the variance of $\left(\zeta_{t}-\zeta_{t}^{*}\right)$, the deviation of the real wage from its equilibrium value. Thus, as indicated by Proposition 1, a variance tradeoff exists unless wages are completely flexible. This tradeoff results from the final term $\kappa_{p}\left(\zeta_{t}-\zeta_{t}^{*}\right)$ in equation (34), rather than the ad hoc residual $\phi_{t}$ in equation (33). Furthermore, the tradeoff depends on the preference and technology parameters of the model as well as the exogenous disturbances $u_{t}, x_{t}$, and $z_{t}$.

Another approach frequently taken in the literature has been to generate a price inflation-output gap variance tradeoff by assuming staggered wage setting with completely flexible prices. ${ }^{22}$ The corresponding special case in our model (that is, $\xi_{w}>0$ and $\xi_{p}=0$ ) exhibits such a tradeoff: equation (32) indicates that by stabilizing the output gap, the monetary authority also stabilizes the nominal wage, so that real wage adjustment in response to a shock must occur through price changes. Nevertheless, this tradeoff has no consequences for social welfare when prices are completely flexible, because price inflation variability does not enter the welfare function. Thus, as indicated in Proposition 2, the Pareto optimum can be obtained in this case by completely stabilizing wage inflation and the output gap.

\section{Optimal Monetary Policy}

In this section we use numerical methods to characterize optimal monetary policy. In particular, for specified values of the structural parameters, we find the interest rate

\footnotetext{
${ }^{22}$ Macroeconomists began to focus on this result in the mid 1970s in the aftermath of the first oil price shock, and Bean (1983) provides a lucid early exposition. The result is emphasized in the various contributions in Bryant, Hooper, and Mann (1993) and in Levin (1989), Henderson and McKibbin (1993), Blanchard (1997), and Friedman (1999).
} 
rule that maximizes the welfare function (30) subject to the log-linearized behavioral equations given in Table 1. For the sake of brevity and clarity, we focus exclusively on volatility induced by exogenous productivity shocks; consumption and leisure shocks imply qualitatively similar properties of the monetary policy frontier. ${ }^{23}$

\subsection{Parameterization and Computation}

Throughout this section, we use a discount factor $\beta$ of 0.99 (corresponding to a quarterly periodicity of the model), and we use household utility parameters $\sigma=$ $\chi=1.5$ (so that utility is nearly logarithmic in consumption and leisure). Unless otherwise specified, the Cobb-Douglas capital share parameter $\alpha=0.3$ (implying that output has a labor elasticity of 0.7 ); the wage and price markup rates $\theta_{w}=\theta_{p}=\frac{1}{3}$; and the wage and price contract duration parameters $\xi_{w}=\xi_{p}=0.75$ (implying an average contract duration of $1 /(1-0.75)=4$ quarters $)$. We assume that the productivity shock $x_{t}$ follows a $\mathrm{AR}(1)$ process with first-order autocorrelation of 0.95 . The variance of the productivity innovation is set to $1.0 \times 10^{-5}$, which implies that $4 y_{t}^{*}$ (the deviation of Pareto-optimal output from steady state at annual rates) has a standard deviation of about 3.1 percentage points.

The full model consists of the equations in Table 1 and the optimal interest rate rule. Given our assumptions about the exogenous shocks, the general form of the optimal interest rate rule must include two state variables - the lagged real wage $\zeta_{t-1}$ and the lagged productivity shock $x_{t-1}$-as well as the productivity innovation $\varepsilon_{t}$ :

$$
i_{t}=\gamma_{\pi} \pi_{t}+\gamma_{\zeta} \zeta_{t-1}+\gamma_{x} x_{t-1}+\gamma_{\varepsilon} \varepsilon_{t}
$$

It is important to note that this rule includes a fixed coefficient $\gamma_{\pi}$ on current price inflation $\pi_{t}$; this coefficient must be large enough to ensure determinacy (that is, the existence of a unique stationary rational expectations equilibrium). Because the reduced-form solution for $\pi_{t}$ only involves the two state variables $\zeta_{t-1}$ and $x_{t-1}$ and the disturbance $\varepsilon_{t}$, the particular value chosen for $\gamma_{\pi}$ does not affect the reduced form solution when the coefficients $\gamma_{\zeta}, \gamma_{x}$, and $\gamma_{\varepsilon}$ are chosen optimally. ${ }^{24}$

To confirm that the determinacy conditions are satisfied and to compute the reduced-form solution of the model for a given set of parameters, we use the numerical algorithm of Anderson and Moore (1985), which provides an efficient implementation of the method proposed by Blanchard and Kahn (1980). Having obtained the reduced-form solution, it is straightforward to compute the variances of the output gap, price inflation, and wage inflation and hence to evaluate the welfare function (30). For a given set of structural parameters, we use a hill-climbing algorithm to determine the values of the monetary policy parameters $\gamma_{\zeta}, \gamma_{x}$, and $\gamma_{\varepsilon}$ that maximize social welfare. ${ }^{25}$

\footnotetext{
${ }^{23}$ See Erceg, Henderson, and Levin (1998). By taking this approach, we also avoid the need to calibrate a contemporaneous covariance matrix for the three disturbances.

${ }^{24}$ In practice, we fix $\gamma_{\pi}=2$ when determining the optimal interest rate rule. For a more complete discussion of the conditions for determinacy, see Erceg, Henderson, and Levin (1998).

${ }^{25}$ A detailed description of the solution algorithm and recent enhancements may be found in Anderson (1997). Using Matlab version 5.2 on a 400Mhz Pentium II, this algorithm generates the
} 


\subsection{Geometric Representation}

Using the numerical methods described above, we can depict the policymaker's optimization problem geometrically, thereby highlighting the parallels with the standard social planner's problem. In particular, each level set of the welfare function (30) corresponds to an indifference locus and forms a plane in 3-dimensional $\left\{\operatorname{Var}\left(g_{t}\right), \operatorname{Var}\left(\pi_{t}\right), \mathcal{V} a r\left(\omega_{t}\right)\right\}$ space. Since the weight on each variable is negative, social welfare decreases as we shift the indifference locus away from the origin. The behavioral equations in Table 1 determine the boundaries of the policy frontier, that is, the policymaker's opportunity set in $\left\{\mathcal{V} a r\left(g_{t}\right), \mathcal{V}\right.$ ar $\left.\left(\pi_{t}\right), \mathcal{V} a r\left(\omega_{t}\right)\right\}$ space. The policy frontier has the property that the variance of any single variable cannot be reduced without increasing the variance of one or both of the other variables. The optimal monetary policy is found at the point at which the policy frontier is tangent to one of the indifference loci.

Figure 2 portrays 2-dimensional slices of the optimization problem for the calibration described above. For example, the upper-left panel depicts the policy frontier and the relevant indifference locus in terms of $\mathcal{V}$ ar $\left(g_{t}\right)$ and $\mathcal{V}$ ar $\left(\pi_{t}\right)$, holding $\mathcal{V}$ ar $\left(\omega_{t}\right)$ constant at its optimal value. As indicated by Proposition 1 , the policy frontier is downward-sloping, reflecting a non-trivial tradeoff in stabilizing the three variables. As indicated by Proposition 2, it is not feasible to obtain the Pareto-optimal level of welfare (that is, the origin does not lie on the policy frontier). The expected welfare loss compared with the Pareto optimum is about 0.0024 percent of steady-state consumption, and is about one-quarter as large as the baseline estimate of Lucas (1987) for the potential welfare gains from eliminating aggregate consumption fluctuations.

In the special case of staggered price contracts and completely flexible wages (not shown), the policy frontier intersects the $\mathcal{V}$ ar $\left(\omega_{t}\right)$ axis; that is, the policy frontier contains a point at which $\mathcal{V} a r\left(\pi_{t}\right)=\mathcal{V} a r\left(g_{t}\right)=0$ and $\mathcal{V} a r\left(\omega_{t}\right)>0$. In this special case, $\operatorname{Var}\left(\omega_{t}\right)$ has zero weight in the welfare function (30), so that each indifference locus is parallel to the $\operatorname{Var}\left(\omega_{t}\right)$ axis. Thus, the point of tangency occurs where the policy frontier intersects the $\mathcal{V}$ ar $\left(\omega_{t}\right)$ axis, yielding the Pareto-optimal welfare level. Similarly, under staggered wage contracts and completely flexible prices, the Pareto optimum is obtained at the intersection of the policy frontier with the $\mathcal{V} a r\left(\pi_{t}\right)$ axis.

\subsection{Implications of Wage and Price Contract Duration}

As we have seen, the policymaker faces a non-trivial stabilization problem when both wages and prices are determined by staggered contracts. Now we use numerical methods to consider a grid of values from 0 to 0.9 for the contract duration parameters $\xi_{w}$ and $\xi_{p}$; that is, for each type of contract, the average duration ranges from one quarter (complete flexibility) up to ten quarters. For each combination of $\xi_{w}$ and $\xi_{p}$, we determine the optimal monetary policy rule and the corresponding implications for aggregate volatility and social welfare.

In Figure 3, panels A, B and $\mathrm{C}$ depict the optimal variance of price inflation, wage inflation, and the output gap, respectively, while panel D depicts the welfare losses

rational expectations solution within a few seconds for every case considered here. 
(as a fraction of steady-state consumption) incurred under the optimal policy relative to the Pareto optimum; Each contour line indicates the combinations of wage and price contract durations under which the optimal policy yields the specified variance (multiplied by $10^{-8}$ ) or welfare loss (multiplied by $10^{-5}$ ).

The contour plots highlight three important points about optimal monetary policy. First, when only one nominal variable is sticky, it is possible to completely smooth variation in that variable, and hence to achieve the Pareto optimal welfare level. The vertical axis corresponds to the special case of the model in which prices are sticky, but wages are fully flexible. The optimal variance of both price inflation (panel A) and the output gap (panel $\mathrm{C}$ ) are clearly zero along this axis. Although the variance of wage inflation reaches its maximum value (panel B), welfare does not depend on wage variation in this case, so that welfare losses are zero (panel D). The horizontal axis corresponds to the symmetric special case in which wages are sticky, but prices are fully flexible. Note that wage inflation and output gap variance are zero along the horizontal axis, while price inflation variance reaches its maximum.

Second, it is optimal ceteris paribus for the more flexible nominal variable (that is, the variable with the shorter contract duration) to bear a relatively larger share of the burden of achieving real wage adjustment. Thus, the optimal variance of price inflation rises as wage contracts lengthen (for a given mean length of price contract), or as the duration of price contracts shortens (for a given mean duration of wage contract). This property is evident from the upward-sloping contour lines for price inflation variance in panel $\mathrm{A}$, and the fact that contour lines associated with relatively high variance lie to the southeast of contour lines associated with lower variance. The contour lines for wage inflation variance in panel B are also upward-sloping, but in this case contour lines to the northwest indicate regions of relatively higher wage inflation variance. Taken together, panels A and B indicate that price inflation variation is relatively low and wage inflation is relatively high in the northwest quadrant, where the mean duration of price contracts is substantially longer than that of wage contracts. In the southeast quadrant, where the mean duration of wage contracts is longer than that of price contracts, wage inflation variability is relatively low and price inflation variability is relatively high.

Third, panel $\mathrm{C}$ indicates that when wage and price contracts have roughly equal duration, i.e., along the main diagonal, output gap volatility is extremely low. This suggests that output gap targeting may have appealing welfare implications if both mean contract duration parameters and other components of the weights on price and wage inflation volatility in the welfare function are similar. On the other hand, when there is considerable asymmetry between the duration of price and wage contracts (as in the northwest or southeast quadrants), it is optimal to allow the output gap to vary, accounting for the two nodes of noticeable output gap variation in the northwest and southeast quadrants. 


\section{Alternative Monetary Policy Rules}

Under staggered price setting and completely flexible wages, we have seen that monetary policy can obtain the Pareto optimum by completely stabilizing price inflation and the output gap while allowing nominal wages to vary freely. Similar results in the existing literature have provided a rationale for strict price inflation targeting, in which the policymaker focuses exclusively on keeping price inflation at or near its target rate. ${ }^{26}$ As indicated in the discussion of equation (31), these results could also be used to justify a strategy of strict output gap targeting.

In contrast, when both wages and prices are determined by staggered contracts, we have shown that the Pareto optimum is infeasible, and that the optimal monetary policy rule is associated with non-zero variance of all three variables $\left(\pi_{t}, g_{t}\right.$, and $\left.\omega_{t}\right)$ that enter the welfare function (30). Now we use numerical methods to evaluate the welfare costs of monetary policy rules that focus exclusively on either price inflation or the output gap, and we determine the extent to which the policymaker can approach the optimal level of social welfare by responding to both variables.

Figure 4 is helpful in identifying the structural parameters that affect the welfare costs of strict price inflation targeting. As in Figure 1, we assume that the economy was previously at the Pareto-optimal equilibrium indicated by point $A$ (that is, $\zeta_{t-1}=$ $\zeta_{t-1}^{*}$ and $\left.g_{t-1}=0\right)$. In the current period, a shock shifts the $m p l_{t}$ and $m r s_{t}$ schedules defined by equations (T1.2) and (T1.3), so that the new Pareto-optimal equilibrium is at point $B$. Under complete price inflation stabilization (that is, $\pi_{t}=\pi_{t+1 \mid t}=0$ for every period $t$ ), it is evident from equation (T1.4) that the real wage must lie on the $m p l_{t}$ schedule. In this case, the identity (T1.6) indicates that all real wage adjustment occurs through nominal wage movements. Thus, to determine the equilibrium values of $\zeta_{t}$ and $g_{t}$, it is necessary to consider wage setting behavior.

The $\pi_{t}=0$ schedule in Figure 4 reflects wage setting behavior. ${ }^{27}$ This schedule

\footnotetext{
${ }^{26}$ See, for example, Goodfriend and King (1997) and King and Wolman (1998).

${ }^{27}$ In Erceg, Henderson, and Levin (1998), we present analytical solutions of the model for the three monetary poliy rules: complete stabilization of price inflation, the output gap, and wage inflation, respectively. Here, we briefly describe the derivation of the $\pi=0$ schedule implied by complete stabilization of price inflatiion. First set $\pi_{t}=0$ in equation (T1.6) to obtain the expression $\omega_{t}=\zeta_{t}-\zeta_{t-1}$. Using this expression to replace $\omega_{t}$, and $\omega_{t+1}$ in equation $(T 1.5)$, and using
} equation $(T 1.3)$ to replace $m r s_{t}$ yields

$$
\zeta_{t}=\left(\frac{1}{1+\beta+\kappa_{w}}\right)\left(\zeta_{t-1}+\beta \zeta_{t+1 \mid t}+\kappa_{w} \zeta_{t}^{*}\right)+\left(\frac{\kappa_{w}}{1+\beta+\kappa_{w}}\right)\left(\frac{\chi \bar{\ell}_{\mathrm{L}}}{1-\alpha}+\sigma \bar{\ell}_{C}\right) g_{t}
$$

The solution for $\zeta_{t}$ in Table 2 of Erceg, Henderson, and Levin (1998) implies that with i.i.d. shocks,

$$
\zeta_{t+1 \mid t}=a_{0} \zeta_{t}, \quad a_{0}=1+\frac{1-\beta}{2 \beta}+\frac{\kappa_{W} \Lambda}{2 \alpha \beta}-\sqrt{\left(1+\frac{1-\beta}{2 \beta}+\frac{\kappa_{W} \Delta}{2 \alpha \beta}\right)^{2}-\frac{1}{\beta}}
$$

Therefore, assuming that the economy was in steady state equilibrium in period $t-1$ so that $\zeta_{t-1}=0$, the first expression in the footnote can be rewritten as

$$
\zeta_{t}=\left(\frac{\kappa_{w}}{1+\beta\left(1-a_{0}\right)+\kappa_{w}}\right) \zeta_{t}^{*}++\left(\frac{\kappa_{w}}{1+\beta\left(1-a_{0}\right)+\kappa_{w}}\right)\left(\frac{\chi \bar{\ell}_{\mathrm{L}}}{1-\alpha}+\sigma \bar{\ell}_{C}\right) g_{t}
$$


gives the combinations of the real wage $\zeta_{t}$ and output gap $g_{t}$ that are consistent with the wage setting equation (T1.5) and the identity (T1.6). Point $C$ on this schedule indicates the real wage at $g_{t}=0$. Nominal wage inflation is positive at this point, because households adjust their wage contracts to reduce the gap between $\zeta_{t}$ and $\zeta_{t}^{*}$ (and hence between $\zeta_{t}$ and $m r s_{t}$ ). Thus, point $C$ lies partway between point $A$ (at which the real wage would remain unchanged) and point $B$ (at which the real wage would equal $\zeta_{t}^{*}$ ), and the relative distance is primarily determined by $\kappa_{w}$, the responsiveness of nominal wage inflation to the $m r s_{t}$ gap. The slope of the $\pi_{t}=0$ schedule is increasing in the value of $\kappa_{w}$ as well as in the slope of the $m r s_{t}$ schedule (that is, the inverse of the elasticity of labor supply with respect to the real wage).

Under strict price inflation targeting, the new equilibrium is at point $D$, the intersection of the $\pi_{t}=0$ schedule with the $m p l_{t}$ schedule. Thus, the costs of strict inflation targeting depend on the slopes of the $m r s_{t}$ and $m p l_{t}$ schedules and on the sensitivity of nominal wages to the current $m r s_{t}$ gap. If the mean wage contract duration is long (that is, only a small fraction of households revise their wage contracts in any given period), then strict inflation targeting is associated with relatively large movements in the output gap and in substantial cross-sectional dispersion in wages and hours worked. Large output and wage fluctuations also occur if the $m p l_{t}$ schedule is relatively flat (corresponding to highly elastic demand for labor).

Similarly, strict output gap targeting can be associated with substantial welfare costs by inducing sub-optimal adjustment of nominal prices and wages. When $g_{t}=0$, equations (T1.2) and (T1.3) indicate that $m p l_{t}=m r s_{t}=\zeta_{t}^{*}$. Substituting these relations into equations (T1.4) and (T1.5), we find that the ratio of price inflation variance to wage inflation variance is simply $\left(\frac{\kappa_{p}}{\kappa_{w}}\right)^{2}$. Thus, the costs of strict output gap targeting depend on the extent to which this ratio differs from the relative weights on $\operatorname{Var}\left(\pi_{t}\right)$ and $\operatorname{Var}\left(\omega_{t}\right)$ in the welfare function (30). For example, as seen from the definitions of $\kappa_{p}$ and $\kappa_{w}$ in Table 1 , neither coefficient depends on the price markup rate $\theta_{p}$, whereas the welfare cost of price inflation volatility increases non-linearly with the price markup rate. Thus, if the degree of substitutability across differentiated goods were much greater than the degree of substitutability across differentiated labor inputs (that is, $\theta_{p} \ll \theta_{w}$ ), then strict output gap targeting would tend to induce excessive price inflation variability compared with the optimal policy rule.

To illustrate these points, it is useful to evaluate the performance of strict price inflation targeting and strict output gap targeting for a range of values of three structural parameters: $\xi_{w}, \alpha$, and $\theta_{p}$. In particular, we vary each parameter in turn, while the other two parameters and all other structural parameters are set at the baseline values indicated in Section 5.1. We use the numerical methods described above to compute the welfare losses of each rule (relative to the Pareto optimum), and we compare these losses to those of the optimal monetary policy rule. We also analyze a hybrid rule in which the interest rate responds to the current price inflation rate

which is the $\pi=0$ schedule. Note that if wages are completely flexible $\left(\kappa_{w} \rightarrow \infty\right)$, the $\pi=0$ schedule is the same as $m r s_{t}$ schedule (T1.3) so the real wage jumps to its new Pareto equilibrium value and that if wages are very slow to adjust $\left(\kappa_{w} \rightarrow 0\right), \zeta_{t} \rightarrow 0$ indicating that the real wage remains very close to its initial steady state. 
and the current output gap; this hybrid rule is similar to those considered recently by several analysts, except that the two coefficients are chosen to maximize the welfare function (30). ${ }^{28}$ These coefficients (as well as those of the optimal policy rule) are recomputed for each set of structural parameters.

\section{Table 2: Welfare Costs of Alternative Policy Rules}

(deviation from Pareto Optimum as a fraction of steady-state consumption) $\times 10^{-5}$

$\begin{array}{ccccc}\text { Wage Contract Mean } & \begin{array}{c}\text { Optimal } \\ \text { Policy Rule }\end{array} & \begin{array}{c}\text { Strict Price } \\ \text { Inflation Target }\end{array} & \begin{array}{c}\text { Strict Output } \\ \text { Gap Target }\end{array} & \begin{array}{r}\text { Hybri } \\ \text { Rule }\end{array} \\ \text { Duration }\left(1-\xi_{w}\right)^{-1} & & & & \\ 1 & 0 & 0 & 0 & 0 \\ 2 & 1.6 & 6.5 & 1.6 & 1.6 \\ 4 & 2.4 & 18.6 & 2.4 & 2.4 \\ 8 & 2.7 & 36.8 & 2.7 & 2.7\end{array}$

Labor Elasticity

of Output $(\alpha)$

0

0.1

0.2

0.3

0.4

0.5

Price Markup

Rate $\left(\theta_{p}\right)$

0.01

0.05

0.10

0.25

0.50
2.2

2.3

2.4

2.4

2.4

2.3

13.0

7.3

5.0

2.9

1.9
702.5

77.8

33.5

18.6

11.3

7.22
2.2

2.3

2.4

2.4

2.5

2.5

50.9

10.9

5.9

2.9

1.9
2.2

2.3

2.4

2.4

2.5

2.5

\section{0}

2.4

2.7 
gap targeting does nearly as well as the optimal rule in the upper two panels, but generates substantial welfare costs when the price markup rate is much smaller than the wage markup rate (that is, when $\theta_{p}$ is small). Finally, the hybrid rule (in which the interest rate responds to both price inflation and the output gap) performs nearly as well as the optimal rule in all cases, despite the absence of the two lagged state variables in this rule.

\section{Conclusions}

When both wages and prices are determined by staggered nominal contracts, we have shown that monetary policy cannot achieve the Pareto-optimal welfare level, and that the optimal policy rule depends on the underlying structure and parameter values of the model. The Pareto optimum is only feasible if either wages or prices are completely flexible. Thus, while considerations of parsimony alone might suggest an exclusive focus on either staggered price setting or staggered wage setting, the inclusion of both types of nominal inertia makes a critical difference in the monetary policy problem.

More generally, our analysis highlights two key features of nominal inertia that generate a non-trivial monetary stabilization problem: the prices of several inputs and/or outputs must be determined by nominal contracts that are not completely synchronized, and the relative prices of some of these inputs and outputs must vary in response to exogenous shocks in the Pareto-optimal equilibrium. These conditions are satisified in our model with staggered wage and price setting. In contrast, in the special case of staggered price setting and completely flexible wages, these conditions are not satisifed because the Pareto-optimal relative prices of the differentiated goods are invariant to aggregate shocks.

These considerations indicate that the existence of a monetary policy tradeoff is not contingent on our particular specification of staggered wage and price setting. Thus, it will be useful to investigate the properties of this tradeoff using alternative formulations of nominal inertia. For example, in a model with differentiated goods at multiple stages of production, the Pareto optimum would be infeasible if the prices of both intermediate inputs and final goods were determined by staggered nominal contracts. In a model with homogenous inputs and differentiated products, the Pareto optimum would be infeasible under one-period input price contracts and staggered output price contracts. Finally, even in the special case of staggered output price setting and completely flexible input prices, monetary policy would be unable to achieve the Pareto optimum if differentiated goods producers faced idiosyncratic productivity shocks or shifts in relative demand.

Although it is worthwhile to consider alternative formulations of nominal inertia, we believe that both wages and prices are sticky in actual economies, and that the relative price of labor plays an important role in generating a non-trivial policy tradeoff. Our position is consistent with the long history of analyses (dating back at least to Keynes (1935)) in which nominal wage inertia plays a significant role in generating aggregate fluctuations. In contrast, recent contributions have emphasized sticky 
prices rather than sticky wages, at least in part because state-contingent employment contracts can, in principle, prevent any misallocation of labor due to nominal wage contracts. ${ }^{30}$ However, one can also imagine state-contingent output contracts which ensure that sticky prices have no allocative effects; such state-contingent contracts are neither more nor less plausible than the analogous employment contracts. Hence, it seems reasonable to assume that both wage and price contracts have significant allocative effects, at least until further guidance is provided by empirical research.

Our analysis suggests several other issues that merit further investigation. First, it will be useful to consider the properties of optimal monetary policy in models with more complicated dynamics due to capital accumulation, adjustment costs, and habit persistence. Second, our analysis has proceeded under the strong informational assumption that all current variables and shocks are observable both to agents and to the policymaker; by relaxing this assumption, subsequent research can analyze the monetary policy implications that arise when variables such as the output gap are subject to persistent measurement errors. Third, a promising direction for future research would be to characterize optimal monetary policy in a model with endogenous determination of the duration of wage and price contracts. ${ }^{31}$ Finally, the welfare costs of output gap deviations are likely to be sensitive to our assumption of complete consumption risk-sharing across households. Allowing for incomplete asset markets could significantly heighten the welfare costs of aggregate fluctuations.

\footnotetext{
${ }^{30}$ Barro (1977) is sometimes cited to support this view. However, Barro himself applies this argument to prices as well as wages.

${ }^{31}$ Studies of the effect of changes in monetary policy on contract length include Canzoneri (1980), Gray (1978), and Dotsey, King, and Wolman (1997) .
} 


\section{Appendix A}

In this appendix, we derive the wage setting equation $(T 1.5)$, the logarithmic approximation of the household's first-order condition (17).

Using the labor demand equation (12), together with our assumption that $\tau_{w}=$ $\theta_{w}$, equation (17) can be expressed as:

$$
\begin{aligned}
& \mathcal{E}_{t} \sum_{j=0}^{\infty} \beta^{j} \xi_{w}^{j} E_{t}(h) F_{t, t+j} \mathbb{U}_{C, t+j} E_{t}^{\eta}(h) G_{t, t+j}^{\eta} L_{t+j} \\
& =\mathcal{E}_{t} \sum_{j=0}^{\infty} \beta^{j} \xi_{w}^{j} \mathbb{H}_{t+j}(h) E_{t}^{\eta}(h) G_{t, t+j}^{\eta} L_{t+j}
\end{aligned}
$$

where $E_{t}(h)=\frac{W_{t}(h)}{W_{t}}, F_{t, t+j}=\frac{W_{t} \Pi^{j}}{P_{t+j}}, G_{t, t+j}=\frac{W_{t} \Pi^{j}}{W_{t+j}}, \mathbb{H}_{t+j}(h)=-\mathbb{V}_{\mathrm{L}, t+j}(h)$, and $\eta=-\left(\frac{1+\theta_{w}}{\theta_{w}}\right)$. Note that $\bar{E}=\bar{G}=1$, and that $\bar{F} \overline{\mathbb{U}}_{C}=-\overline{\mathbb{V}}_{\mathrm{L}}=\overline{\mathbb{H}}$, because the steady state satisfies the complete-flexibility condition (18).

Taking the log differential of equation (A.1), and using these relations to cancel identical terms, we obtain:

$$
\frac{1}{1-\xi_{w} \beta} e_{t}(h)+\mathcal{E}_{t} \sum_{j=0}^{\infty} \xi_{w}^{j} \beta^{j}\left(f_{t, t+j}+\widehat{\mathbb{U}}_{C, t+j}\right)=\mathcal{E}_{t} \sum_{j=0}^{\infty} \xi_{w}^{j} \beta^{j} \widehat{\mathbb{H}}_{t+j}(h)
$$

where each lower-case letter denotes the deviation of the logarithm of the variable from its steady-state value, except that we use $\widehat{\mathbb{U}}_{C, t+j}$ and $\widehat{\mathbb{H}}_{t+j}(h)$ to denote the logarithmic deviation of these variables from $\overline{\mathbb{U}}_{C}$ and $\overline{\mathbb{H}}$, respectively.

Now we express this relationship as a discounted sum of current and future gaps between the aggregate real wage $\zeta_{t}$ and the population average $m r s_{t}=\widehat{\mathbb{H}}_{t}-\widehat{\mathbb{U}}_{C, t}$ (defined by evaluating equation (19) at the average hours of labor $L_{t}$ ). From the household's utility function (13), it is evident that $\widehat{\mathbb{H}}_{t+j}(h)=\chi\left(\bar{\ell}_{L} \mathrm{l}_{t}(h)+\bar{\ell}_{Z} z_{t}\right)$ for each household $h$, and that (to a first-order approximation) the cross-section average $\widehat{\mathbb{H}}_{t+j}=\chi\left(\bar{\ell}_{L} l_{t}+\bar{\ell}_{Z} z_{t}\right)$. Furthermore, the labor demand equation (12) indicates that $\mathrm{I}_{t+j}(h)=l_{t+j}+\eta\left(e_{t}(h)+g_{t, t+j}\right)$ for each household $h$ whose wage contract signed at date $t$ remains in effect at date $t+j$. Finally, it is evident that the real wage deviation from steady state satisfies $\zeta_{t+j}=f_{t, t+j}-g_{t, t+j}$ and that $g_{t, t}=0$. Substituting these relationships into equation (A.2) yields:

$$
\left(1-\eta \chi \bar{\ell}_{L}\right)\left(\frac{e_{t}(h)}{1-\xi_{w} \beta}+\mathcal{E}_{t} \sum_{j=1}^{\infty} \xi_{w}^{j} \beta^{j} g_{t, t+j}\right)=\mathcal{E}_{t} \sum_{j=0}^{\infty} \xi_{w}^{j} \beta^{j}\left(m r s_{t+j}-\zeta_{t+j}\right)
$$

Finally, we express this relation in terms of the wage inflation deviation $\omega_{t}$. The aggregate wage definition $W_{t}=\left(1-\xi_{w}\right) W_{t}(h)+\xi_{w}\left(W_{t-1}+\Pi\right)$ directly implies (to a first-order approximation) that $e_{t}(h)=\frac{\xi_{w}}{1-\xi_{w}} \omega_{t}$. Finally, by noting that $g_{t, t+j}=$ $-\sum_{k=1}^{j} \omega_{t+k}$ and rearranging terms, it is straightforward to obtain equation $(T 1.5)$. 


\section{Appendix B}

In this appendix, we derive the approximation for $\mathbb{W}_{t}-\mathbb{W}_{t}^{*}$ given in equation (24). To express $\mathcal{E}\left(\mathbb{W}_{t}-\mathbb{W}_{t}^{*}\right)$ in terms of aggregate volatilities, as given in equation (30), three additional results are needed: (1) $\mathcal{E} g_{t}^{2}=\mathcal{V} a r\left(g_{t}\right)$; (2) $\mathcal{E} \operatorname{var}_{h} w(h)=$ $\frac{\xi_{w}}{\left(1-\xi_{w}\right)^{2}} \mathcal{V} a r\left(\omega_{t}\right)$; and $(3) \mathcal{E} \operatorname{var}_{f} y(f)=\frac{\xi_{w}}{\left(1-\xi_{w}\right)^{2}} \mathcal{V}$ ar $\left(\pi_{t}\right)$. This appendix provides proofs for the first two results; the proof of the third result (which is virtually identical to that of the second) may be found in Rotemberg and Woodford (1998b). Throughout this appendix, we make use of second-order Taylor approximations.

We make repeated use of two approximations. Let $A$ be a generic variable. The arithmetic percentage change in $A$ has the following relation to the logarithmic percentage change:

$$
\frac{A-\bar{A}}{\bar{A}}=\frac{d A}{\bar{A}} \simeq a+\frac{1}{2} a^{2}, \quad a \equiv \ln A-\ln \bar{A}
$$

Next consider the case in which $A=\left[\int_{0}^{1} A(j)^{\phi}\right]^{\frac{1}{\phi}}$. Then the logarithmic approximation of $A$ is

$$
a \simeq \mathcal{E}_{j} a(j)+\frac{1}{2} \phi\left(\mathcal{E}_{j} a(j)^{2}-\left(\mathcal{E}_{j} a(j)\right)^{2}\right)=\mathcal{E}_{j} a(j)+\frac{1}{2} \phi v a r_{j} a(j)
$$

\section{The Derivation of the Approximation of $\frac{\mathbb{W}-\mathbb{W}^{*}}{\mathbb{U}_{\mathrm{C}} \overline{\mathrm{C}}}$}

Equation (23) is repeated here for convenience:

$$
\mathbb{W}=\mathbb{U}(C, U)+\int_{0}^{1} \mathbb{V}(L(h), Z) d h
$$

where time subscripts are omitted for notational simplicity. We approximate the two parts separately and combine the results at the end. First, consider the approximation of $\mathbb{U}(C, U)$ :

$$
\begin{aligned}
\mathbb{U}(C, U) & \simeq \overline{\mathbb{U}}+\mathbb{U}_{C} \bar{C} \frac{d C}{\bar{C}}+\mathbb{U}_{U} \bar{U} \frac{d U}{\bar{U}} \\
& +\frac{1}{2}\left(\mathbb{U}_{C C} \bar{C}^{2}\left(\frac{d C}{\bar{C}}\right)^{2}+2 \mathbb{U}_{C U} \bar{C} \bar{U} \frac{d C}{\bar{C}} \frac{d U}{\bar{U}}+\mathbb{U}_{U U} \bar{U}^{2}\left(\frac{d U}{\bar{U}}\right)^{2}\right)
\end{aligned}
$$

Making use of the result in equation (B.1) yields

$$
\begin{aligned}
& \mathbb{U}(C, U) \simeq \overline{\mathbb{U}}+\mathbb{U}_{C} \bar{C}\left(y+\frac{1}{2} y^{2}\right)+\mathbb{U}_{U} \bar{U}\left(u+\frac{1}{2} u^{2}\right) \\
& +\frac{1}{2}\left(\mathbb{U}_{C C} \bar{C}^{2} y^{2}+2 \mathbb{U}_{C U} \bar{C} \bar{U} y u+\mathbb{U}_{U U} \bar{U}^{2} u^{2}\right)
\end{aligned}
$$

Now consider an approximation to $\int_{0}^{1} \mathbb{V}(\mathrm{L}(h), Z) d h$ : 


$$
\begin{aligned}
& \int_{0}^{1} \mathbb{V}(\mathrm{L}(h), Z) d h \simeq \overline{\mathbb{V}}+\int_{0}^{1} \mathbb{V}_{L} \overline{\mathrm{L}} \frac{d \mathbf{L}(h)}{\overline{\mathrm{L}}} d h+\mathbb{V}_{Z} \bar{Z} \frac{d Z}{\bar{Z}} \\
& \quad+\frac{1}{2}\left(\int_{0}^{1} \mathbb{V}_{L L} \overline{\mathrm{L}}^{2}\left(\frac{d \mathbf{L}(h)}{\overline{\mathrm{L}}}\right)^{2} d h+\int_{0}^{1} \mathbb{V}_{L Z} \overline{\mathrm{L}} \bar{Z} \frac{d \mathbf{L}(h)}{\overline{\mathrm{L}}} \frac{d Z}{\bar{Z}} d h+\mathbb{V}_{Z Z} \bar{Z}^{2}\left(\frac{d Z}{\bar{Z}}\right)^{2}\right)
\end{aligned}
$$

Making use of the result in equation (B.1) yields

$$
\begin{aligned}
\int_{0}^{1} \mathbb{V}(\mathrm{L}(h), Z) d h \simeq \overline{\mathbb{V}}+\mathbb{V}_{L} \overline{\mathrm{L}}\left(\mathcal{E}_{h} \mathrm{I}(h)+\frac{1}{2} \mathcal{E}_{h} \mathrm{I}(h)^{2}\right)+\mathbb{V}_{Z} \bar{Z}\left(z+\frac{1}{2} z^{2}\right) \\
+\frac{1}{2}\left(\mathbb{V}_{\mathrm{LL}} \overline{\mathrm{L}}^{2} \mathcal{E}_{h} \mathrm{I}(h)^{2}+2 \mathbb{V}_{\mathrm{L} Z} \overline{\mathrm{L}} \bar{Z} z \mathcal{E}_{h} \mathrm{I}(h)+\mathbb{V}_{Z Z} \bar{Z}^{2} z^{2}\right)
\end{aligned}
$$
Thus,

The index $L$ aggregates labor hours across households: $L=\left[\int_{0}^{1} L(h)^{\frac{1}{1+\theta_{w}}}\right]^{1+\theta_{W}}$.

$$
l=\ln \left[\int_{0}^{1} \mathrm{~L}(h)^{\frac{1}{1+\theta_{w}}}\right]^{1+\theta_{w}}-\ln \bar{L} \simeq \mathcal{E}_{h} \mathbf{I}(h)+\frac{1}{2}\left(\frac{1}{1+\theta_{w}}\right) \operatorname{var}_{h} \mathrm{I}(h)
$$

The index $L$ is also the sum of labor services used by firms: $L=\int_{0}^{1} L(f) d f$. Thus,

$$
l=\ln \int_{0}^{1} L(f) d f-\ln \bar{L} \simeq \mathcal{E}_{f} l(f)+\frac{1}{2} \operatorname{var}_{f} l(f)
$$

All firms choose identical capital labor ratios $\left(\frac{K(f)}{L(f)}\right)$ equal to the aggregate ratio $\left(\frac{K}{L}\right)$ because they face the same factor prices, so

$$
Y(f)=\left(\frac{K(f)}{L(f)}\right)^{\alpha} L(f) X=\left(\frac{K}{L}\right)^{\alpha} L(f) X
$$

Since the total amount of capital is fixed, equation (B.10) in turn implies

$$
y(f)=x-\alpha l+l(f), \quad \mathcal{E}_{f} y(f)=x-\alpha l+\mathcal{E}_{f} l(f), \quad \operatorname{var}_{f} y(f)=\operatorname{var}_{f} l(f)
$$

Substituting the relationships in equation (B.11) into equation (B.9), and using equation (B.2) to substitute for $\mathcal{E}_{f} y(f)$, we obtain equation (26) in the text, repeated here for convenience:

$$
l \simeq \frac{1}{1-\alpha}(y-x)+\frac{1}{2}\left(\frac{1}{1-\alpha}\right)\left(\frac{\theta_{p}}{1+\theta_{p}}\right) \operatorname{var}_{f} y(f)
$$

Solving equation (B.8) for $\mathcal{E}_{h} \mathrm{I}(h)$ and eliminating $l$ using equation (B.12) yields

$$
\mathcal{E}_{h} \mathrm{I}(h) \simeq \frac{1}{1-\alpha}(y-x)+\frac{1}{2}\left(\frac{1}{1-\alpha}\right)\left(\frac{\theta_{p}}{1+\theta_{p}}\right) \operatorname{var}_{f} y(f)-\frac{1}{2}\left(\frac{1}{1+\theta_{w}}\right) \operatorname{var}_{h} \mathrm{I}(h)
$$

Using equation (B.2), the term $\operatorname{var}_{h} \mathbf{I}(h)+\left[\mathcal{E}_{h} \mathbf{I}(h)\right]^{2}$ can be substituted for each occurrence of $\mathcal{E}_{h} \mathrm{I}(h)^{2}$ in equation (B.7). Then substituting the right-hand side of equation (B.13) for each occurrence of $\mathcal{E}_{h} \mathrm{I}(h)$, we obtain: 


$$
\begin{aligned}
& \int_{0}^{1} \mathbb{V}(\mathrm{L}(h), Z) d h \simeq \overline{\mathbb{V}}+\mathbb{V}_{Z} \bar{Z} z+\mathbb{V}_{\mathrm{L}} \overline{\mathrm{L}}\left(\frac{y-x}{1-\alpha}\right) \\
& +\frac{1}{2}\left[\left(\mathbb{V}_{Z} \bar{Z}+\mathbb{V}_{Z Z} \bar{Z}^{2}\right) z^{2}+2 \mathbb{V}_{\mathrm{L} Z} \overline{\mathrm{L}} \bar{Z}\left(\frac{(y-x) z}{1-\alpha}\right)+\left(\mathbb{V}_{\mathrm{L}} \overline{\mathrm{L}}+\mathbb{V}_{\mathrm{LL}} \overline{\mathrm{L}}^{2}\right)\left(\frac{y-x}{1-\alpha}\right)^{2}\right. \\
& \left.+\left(\mathbb{V}_{\mathrm{L}} \overline{\mathrm{L}}\left(\frac{\theta_{w}}{1+\theta_{w}}\right)+\mathbb{V}_{\mathrm{LL}} \overline{\mathrm{L}}^{2}\right) \operatorname{var}_{h} \mathrm{I}(h)+\left(\frac{\mathbb{V}_{\mathrm{L}} \overline{\mathrm{L}}}{1-\alpha}\right)\left(\frac{\theta_{p}}{1+\theta_{p}}\right) \operatorname{var}_{f} y(f)\right]
\end{aligned}
$$

Approximating the utility associated with consumption and labor in the Pareto optimum allocation, $\mathbb{U}\left(C^{*}, U\right)$ and $\int_{0}^{1} \mathbb{V}\left(\mathrm{L}(h)^{*}, Z\right) d h$, respectively, in analogous ways and subtracting the sum of the results from the sum of equations $(B .5)$ and $(B .14)$ yields the approximation for $\mathbb{W}-\mathbb{W}^{*}$ :

$$
\begin{aligned}
\mathbb{W} & -\mathbb{W}^{*} \simeq\left(\mathbb{U}_{C} \bar{C}+\frac{\mathbb{V}_{\mathrm{L}} \overline{\mathrm{L}}}{1-\alpha}\right)\left(y-y^{*}\right) \\
& +\left[\mathbb{U}_{C U} \bar{C} \bar{U} u+\frac{\mathbb{V}_{\mathrm{L} Z} \overline{\mathrm{L}} \bar{Z}}{1-\alpha} z-\frac{\mathbb{V}_{\mathrm{L}} \overline{\mathrm{L}}+\mathbb{V}_{\mathrm{L}} \overline{\mathrm{L}}^{2}}{(1-\alpha)^{2}} x\right]\left(y-y^{*}\right) \\
& +\frac{1}{2}\left(\mathbb{U}_{C} \bar{C}+\mathbb{U}_{C C} \bar{C}^{2}+\frac{\mathbb{V}_{\mathrm{L}} \overline{\mathrm{L}}+\mathbb{V}_{\mathrm{L}} \overline{\mathrm{L}}^{2}}{(1-\alpha)^{2}}\right)\left(y^{2}-y^{* 2}\right) \\
& +\frac{1}{2}\left(\mathbb{V}_{\mathrm{L}} \overline{\mathrm{L}}\left(\frac{\theta_{w}}{1+\theta_{w}}\right)+\mathbb{V}_{\mathrm{LL}} \overline{\mathrm{L}}^{2}\right) \operatorname{var}_{h} \mathrm{I}(h)+\frac{1}{2} \frac{\mathbb{V}_{\mathrm{L}} \overline{\mathrm{L}}}{1-\alpha}\left(\frac{\theta_{p}}{1+\theta_{p}}\right) \operatorname{var}_{f} y(f)
\end{aligned}
$$

Now we give some important steady-state relationships: $\mathbb{U}_{C}=(C-U)^{-\sigma}, \mathbb{U}_{C C}=$ $-\mathbb{U}_{C U}=-\sigma(C-U)^{-\sigma-1}, \mathbb{V}_{\mathrm{L}}=-(1-\mathrm{L}-Z)^{\chi}$, and $\mathbb{V}_{\mathrm{LL}}=V_{\mathrm{L} Z}=-\chi(1-\mathrm{L}-Z)^{\chi-1}$. Thus, $\frac{\mathbb{U}_{C C}}{\mathbb{U}_{C}}=-\frac{\mathbb{U}_{C U}}{\mathbb{U}_{C}}=-\frac{\sigma}{C-U}$ and $\frac{\mathbb{V}_{\mathrm{LL}}}{\mathbb{V}_{\mathrm{L}}}=\frac{\mathbb{V}_{\mathrm{L} Z}}{\mathbb{V}_{\mathrm{L}}}=\frac{\chi}{1-\mathrm{L}-Z}$.

Evaluating the first-order condition (18) at the steady state yields $\mathbb{U}_{C} \bar{C}+\frac{\mathbb{V}_{\mathrm{L}} \overline{\mathrm{L}}}{1-\alpha}=0$, so that the first term in equation (B.15) vanishes. Using the approximation of Paretooptimal output in equation (20), together with the steady-state relationships indicated above, the second line in equation (B.15) equals $\frac{\Lambda \mathbb{U}_{C} \bar{C}}{1-\alpha}\left(y-y^{*}\right) y^{*}$. These steady-state relationships also allow the third line to be expressed as $\frac{\Lambda \mathbb{U}_{C} \bar{C}}{2(1-\alpha)}\left(y^{* 2}-y^{2}\right)$. Combining the second and third lines yields the squared output gap term in equation (24) in the text, while the cross-sectional dispersion terms are given by the final line in equation (B.15).

Using the steady-state relationships, further simplification yields

$$
\begin{aligned}
& \frac{2\left(\mathbb{W}-\mathbb{W}^{*}\right)}{\mathbb{U}_{C} \bar{C}} \simeq-\left(\frac{\alpha}{1-\alpha}+\sigma \bar{\ell}_{C}+\frac{\chi \bar{\ell}_{L}}{1-\alpha}\right) g_{t}^{2} \\
& -(1-\alpha)\left(\frac{\theta_{w}}{1+\theta_{w}}+\chi \ell_{\mathrm{L}}\right) \operatorname{var}_{h} \mathrm{I}(h)-\left(\frac{\theta_{p}}{1+\theta_{p}}\right) \operatorname{var}_{f} y(f)
\end{aligned}
$$

Taking expectations of this equation and using the three results listed at the beginning of this Appendix, we obtain equation (30) in the text. 


\section{Proof That $\mathcal{E} \mathbf{g}_{\mathrm{t}}^{2}=\mathcal{V}$ ar $\left(\mathrm{g}_{\mathrm{t}}\right)$}

In order to prove that $\mathcal{E} g_{t}^{2}=\mathcal{V} a r\left(g_{t}\right)$, we show that $\mathcal{E} g_{t}$ is of second order, so that $\left(\mathcal{E} g_{t}\right)^{2}$ can be neglected in the second-order approximation. We assume that the model has a unique stationary rational expectations solution, and that aggregate output $Y_{t}$ can be expressed as a function of all current and past shocks:

$$
Y_{t}=\Upsilon\left(\tilde{U}_{t}, \tilde{X}_{t}, \tilde{Z}_{t}\right)
$$

where $\tilde{U}_{t}, \tilde{X}_{t}, \tilde{Z}_{t}$ are vectors containing all current and past values of the disturbances. We assume that $\mathcal{E} u_{t}=\mathcal{E} x_{t}=\mathcal{E} z_{t}=0$; for illustrative purposes, we also assume that the disturbances are mutually and serially uncorrelated. Applying expression (B.1) to equation (B.17) and taking unconditional expectations yields

$$
\begin{aligned}
& 2 \mathcal{E}\left(Y_{t}-\bar{Y}\right)=\sum_{j=0}^{\infty}\left[\left(\Upsilon_{U_{t-j}} \bar{U}+\Upsilon_{U_{t-j} U_{t-j}} \bar{U}^{2}\right) \mathcal{V} a r\left(u_{t}\right)\right. \\
& \left.+\left(\Upsilon_{X_{t-j}} \bar{X}+\Upsilon_{X_{t-j} X_{t-j}} \bar{X}^{2}\right) \mathcal{V} a r\left(x_{t}\right)+\left(\Upsilon_{Z_{t-j}} \bar{Z}+\Upsilon_{Z_{t-j} Z_{t-j}} \bar{Z}^{2}\right) \mathcal{V} a r\left(z_{t}\right)\right]
\end{aligned}
$$

Applying expression (B.1) to $Y_{t}$ and taking unconditional expectations yields

$$
2 \mathcal{E}\left(Y_{t}-\bar{Y}\right)=2 \bar{Y} \mathcal{E} y_{t}+\bar{Y} \mathcal{V} a r\left(y_{t}\right)+\bar{Y}\left(\mathcal{E} y_{t}\right)^{2}
$$

Since the right hand side of equation (B.18) is of second order, it follows that $\mathcal{E} y_{t}$ must be of second order. By an analogous line of argument $\mathcal{E} y_{t}^{*}$ must be of second order. Therefore $\mathcal{E} g_{t}=\mathcal{E} y_{t}-\mathcal{E} y_{t}^{*}$ must be of second order.

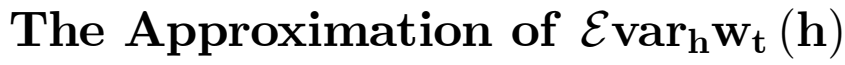

Since $\mathcal{E}_{h} w_{t-1}(h)$ and $\ln \Pi$ are not household-specific,

$$
\begin{aligned}
& \operatorname{var}_{h} w_{t}(h)=\operatorname{var}_{h}\left(w_{t}(h)-\mathcal{E}_{h} w_{t-1}(h)-\ln \Pi\right) \\
& \quad=\mathcal{E}_{h}\left(w_{t}(h)-\mathcal{E}_{h} w_{t-1}(h)-\ln \Pi\right)^{2}-\left(\mathcal{E}_{h} w_{t}(h)-\mathcal{E}_{h} w_{t-1}(h)-\ln \Pi\right)^{2}
\end{aligned}
$$

The first term on the right hand side of equation (B.20) can be rewritten as

$$
\begin{aligned}
& \mathcal{E}_{h}\left(w_{t}(h)-\mathcal{E}_{h} w_{t-1}(h)-\ln \Pi\right)^{2}=\int_{0}^{1}\left(w_{t}(h)-\mathcal{E}_{h} w_{t-1}(h)-\ln \Pi\right)^{2} d h \\
& =\int_{0}^{1-\xi_{W}}\left(\mathrm{w}_{t}-\mathcal{E}_{h} w_{t-1}(h)-\ln \Pi\right)^{2} d h+\int_{1-\xi_{w}}^{1}\left(w_{t-1}(h)-\mathcal{E}_{h} w_{t-1}(h)\right)^{2} d h \\
& =\left(1-\xi_{w}\right)\left(\mathrm{w}_{t}-\mathcal{E}_{h} w_{t-1}(h)-\ln \Pi\right)^{2}+\xi_{w} \operatorname{var}_{h} w_{h, t-1}
\end{aligned}
$$

where $w_{t}$ is the logarithm of the wage set by all the $\left(1-\xi_{w}\right)$ households that reset their wages in the current period. The second term on the middle line equals the second term on the last line because the probability that a household will be allowed 
to reset its wage contract in a given period does not depend on how long its existing contract has been in effect. Thus, the distribution of wages for households not resetting wages is the same as the distribution of wages for all households in the previous period. Next, we note that

$$
\begin{aligned}
& \mathcal{E}_{h} w_{t}(h)-\mathcal{E}_{h} w_{t-1}(h)-\ln \Pi \\
& =\int_{0}^{1-\xi_{w}}\left(\mathbf{w}_{t}-\mathcal{E}_{h} w_{t-1}(h)-\ln \Pi\right) d h-\int_{1-\xi_{w}}^{1}\left(w_{t-1}(h)-\mathcal{E}_{h} w_{t-1}(h)\right) d h, \\
& =\left(1-\xi_{w}\right)\left(\mathbf{w}_{t}-\mathcal{E}_{h} w_{t-1}(h)-\ln \Pi\right)
\end{aligned}
$$

Equation (B.22) can be used to express the contract wage $\mathrm{w}_{t}$ in terms of the average wage $\mathcal{E}_{h} w_{t}(h)$. Substituting this expression into equation (B.21), equation (B.20) can be rewritten as

$$
\operatorname{var}_{h} w_{t}(h)=\frac{1}{1-\xi_{w}} \omega_{t-1}^{2}+\xi_{w} \operatorname{var}_{h} w_{t-1}(h) .
$$

Taking unconditional expectations and rearranging yield

$$
\mathcal{E v a r}_{h} w(h)=\frac{\xi_{w}}{\left(1-\xi_{w}\right)^{2}} \mathcal{E} \omega_{t-1}^{2}=\frac{\xi_{w}}{\left(1-\xi_{w}\right)^{2}} \mathcal{V} a r\left(\omega_{t}\right)
$$

$\mathcal{E} \omega_{t}^{2}=\mathcal{V} a r\left(\omega_{t}\right)$ because $\mathcal{E} \omega_{t}$ is of second order by an argument analogous to the one used for $\mathcal{E} g_{t}$ above. 


\section{References}

Aizenman, J., and J. A. Frenkel (1986) "Wage Indexation, Supply Shocks, and Monetary Policy in a Small Open Economy", in S. Edwards and L. Ahamed (eds.) Economic Adjustment and Exchange Rate Changes in Developing Countries, University of Chicago Press, Chicago.

Anderson, G. S., and G. Moore (1985) "A Linear Algebraic Procedure for Solving Linear Perfect Foresight Models", Economic Letters, 17, 247-52.

Barro, R. J. (1977) "Long-Term Contracting, Sticky Prices, and Monetary Policy", Journal of Monetary Economics, 3, 305316.

Bean, C. (1983) "Targeting Nominal Income: An Appraisal", The Economic Journal, 93, 806-19.

Blanchard, O. (1997) "Comment", in NBER Macroeconomics Annual 1997, MIT Press, 289-295.

Blanchard, O., and C. M. Kahn (1980) "The Solution of Linear Difference Models under Rational Expectations", Econometrica, 48, 1305-11.

Blanchard, O. J., and N. Kiyotaki (1985) "Monopolistic Competition, Aggregate Demand Externalities and Real Effects of Nominal Money", NBER Working Paper 1770, National Bureau of Economic Research.

Blanchard, O. J., and N. Kiyotaki (1987) "Monopolistic Competition and the Effects of Aggregate Demand", American Economic Review, 77, 4, 647-666.

Bryant, R., P. Hooper, and C. Mann (1993) Evaluating Policy Regimes: New Research in Empirical Macroeconomics, Brookings Institution, Washington, D.C.

Calvo, G. (1983) "Staggered Prices in a Utility Maximizing Framework", Journal of Monetary Economics, 12, 383-398.

Canzoneri, M. B. (1980) "Labor Contracts and Monetary Policy", Journal of Monetary Economics, 6, 241245.

Dixit, A. K., and J. Stiglitz (1977) "Monopolistic Competition and Optimum Product Diversity", American Economic Review, 67, 297-308.

Dotsey, M., R. G. King, and A. L. Wolman (1997) "State Dependent Pricing and Dynamics of Business Cycles", Working Paper No. 97-2, Federal Reserve Bank of Richmond.

Erceg, C. J. (1997) "Nominal Wage Rigidities and the Propagation of Monetary Disturbances", International Finance Discussion Papers, No. 590, Federal Reserve Board. 
Erceg, C. J., D. W. Henderson, and A. T. Levin (1998) “Tradeoffs Between Inflation and Output-Gap Variances in a Optimizing-Agent Model", International Finance Discussion Papers, No. 627, Federal Reserve Board.

Friedman, B. (1999) "Comment", in J. Taylor (ed.) Monetary Policy Rules, The University of Chicago Press, Chicago, forthcoming.

Goodfriend, M., and R. King (1997) "The New Neoclassical Synthesis and the Role of Monetary Policy", in NBER Macroeconomics Annual 1997, MIT Press, Cambridge, 233-283.

Gray, J. (1978) "On Indexation and Contract Length", Journal of Political Economy, $86,1-18$.

Henderson, D., and W. McKibbin (1993) "A Comparison of Some Basic Monetary Policy Regimes for Open Economies: Implications of Different Degrees of Instrument Adjustment and Wage Persistence", in Carnegie-Rochester Series on Public Policy, Volume 39, 221-317.

Ireland, P. N. (1997) "A Small Structural, Quarterly Model for Monetary Policy Evaluation", in Carnegie-Rochester Series on Public Policy, Volume 47, 83-108.

Kerr, W., and R. G. King (1996) "Limits on Interest Rate Rules in the IS Model", Federal Reserve Bank of Richmond Economic Quarterly, 82, 47-75.

Keynes, J. M. (1935) The General Theory of Employment, Interest, and Money, Harcourt, Brace, and World, New York.

Kim, J. (1999) "Constructing and Estimating a Realistic Optimizing Model of Monetary Policy", Journal of Monetary Economics, forthcoming.

Kimball, M. S. (1995) "The Quantitative Analysis of the Basic Neomonetarist Model", Journal of Money, Credit, and Banking, 27, 12411277.

King, R. G., and A. L. Wolman (1998) "What Should the Monetary Authority Do When Prices Are Sticky?", in J. Taylor (ed.) Monetary Policy Rules, The University of Chicago Press, Chicago, forthcoming.

Kollmann, R. (1997) "The Exchange Rate in a Dynamic-Optimizing Current Account Model with Nominal Rigidities: A Quantitative Investigation", Working Paper, International Monetary Fund.

Levin, A. (1989) "The Theoretical and Empirical Relevance of Staggered Wage Contract Models", Ph.D. dissertation, Stanford University.

Levin, A., V. Wieland, and J. C. Williams (1998) "Robustness of Simple Monetary Policy Rules under Model Uncertainty", in J. Taylor (ed.) Monetary Policy Rules, The University of Chicago Press, Chicago, forthcoming. 
Lucas, Jr., R. E. (1987) Models of Business Cycles, Basil Blackwell, Oxford.

Phelps, E. S., and J. B. Taylor (1977) "Stabilizing Powers of Monetary Policy under Rational Expectations", Journal of Political Economy, 85, 163-190.

Quandt, R. (1987) "Bibliography on Disequilibrium", processed, Princeton University.

Rotemberg, J., and M. Woodford (1998a) "Interest-Rate Rules in an Estimated Sticky Price Model", in J. Taylor (ed.) Monetary Policy Rules, The University of Chicago Press, Chicago, forthcoming.

Rotemberg, J. J. (1996) "Prices, Output, and Hours: An Empirical Analysis Based on a Sticky Price Model", Journal of Monetary Economics, 37, 505533.

Rotemberg, J. J., and M. Woodford (1998b) "An Optimization-Based Econometric Framework for the Evaluation of Monetary Policy", in NBER Macroeconomics Annual 1997, MIT Press, Cambridge, 297-346.

Rudebusch, G. D., and L. E. O. Svensson (1998) "Policy Rules for Inflation Targeting", in J. Taylor (ed.) Monetary Policy Rules, The University of Chicago Press, Chicago, forthcoming.

Solow, R., and J. Stiglitz (1968) "Output, Employment, and Wages in the Short Run", Quarterly Journal of Economics, 82, 537-560.

Taylor, J. (1979) "Staggered Contracts in a Macro Model", American Economic Review, 69, 108-113.

Taylor, J. (1980) "Aggregate Dynamics and Staggered Contracts", Journal of Political Economy, 88, 1-24.

Taylor, J. B. (1993) "Discretion versus Policy Rules in Practice", in CarnegieRochester Series on Public Policy, Volume 39, 195-214.

Tetlow, R., and P. von zur Muehlen (1996) "Monetary Policy Rules in a Small Forward-Looking Maco Model", processed, Federal Reserve Board.

Williams, J. C. (1997) "Simple Rules for Monetary Policy", processed, Federal Reserve Board.

Woodford, M. (1996) "Control of the Public Debt: A Requirement for Price Stability?", NBER Working Paper 5684, National Bureau of Economic Research.

Yun, T. (1996) "Nominal Price Rigidity, Money Supply Endogeneity, and Business Cycles", Journal of Monetary Economics, 37, 345-370. 


\section{Figure 1: Welfare Costs of Output Gap Deviations}

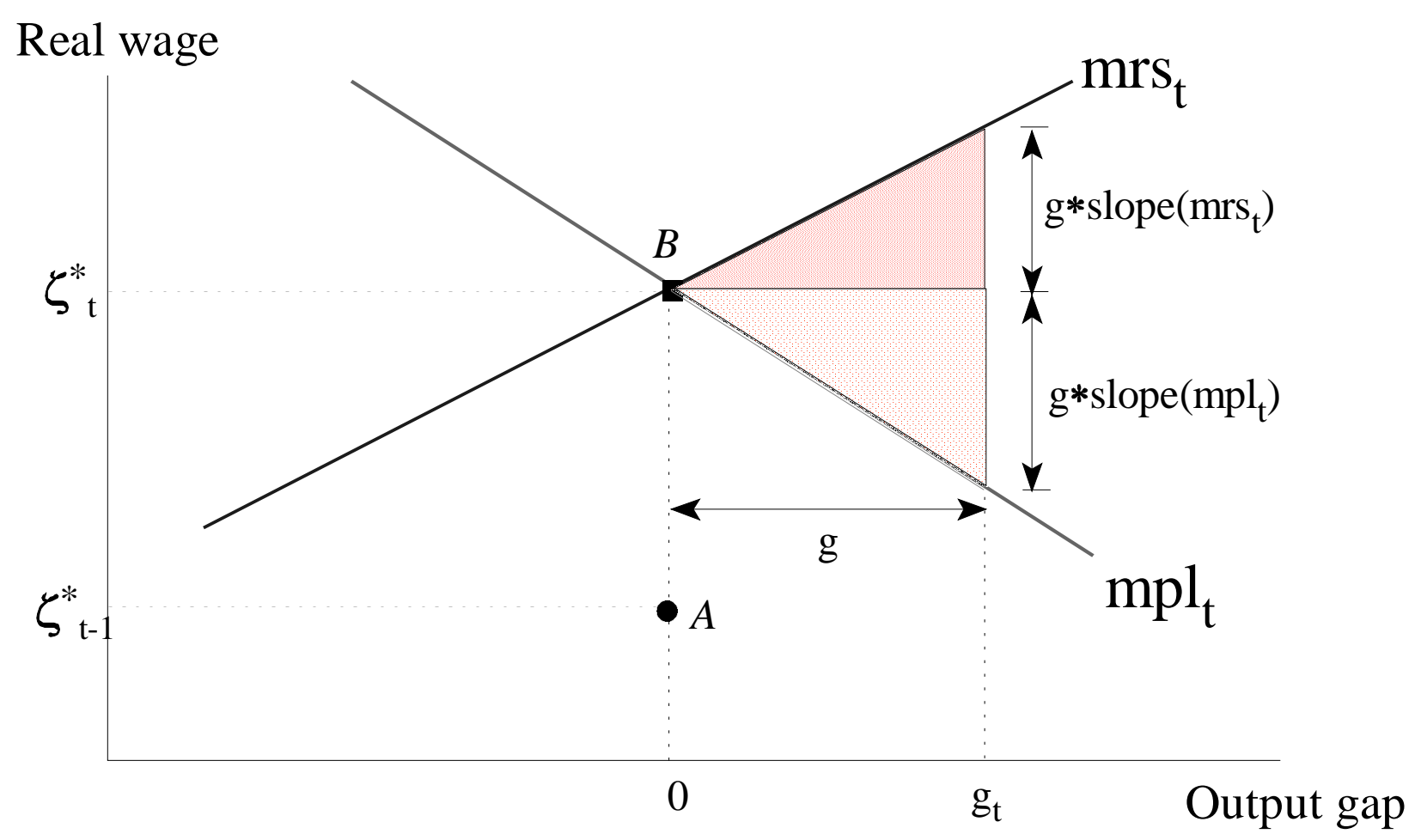


Figure 2

Three Views of the Monetary Policy Frontier
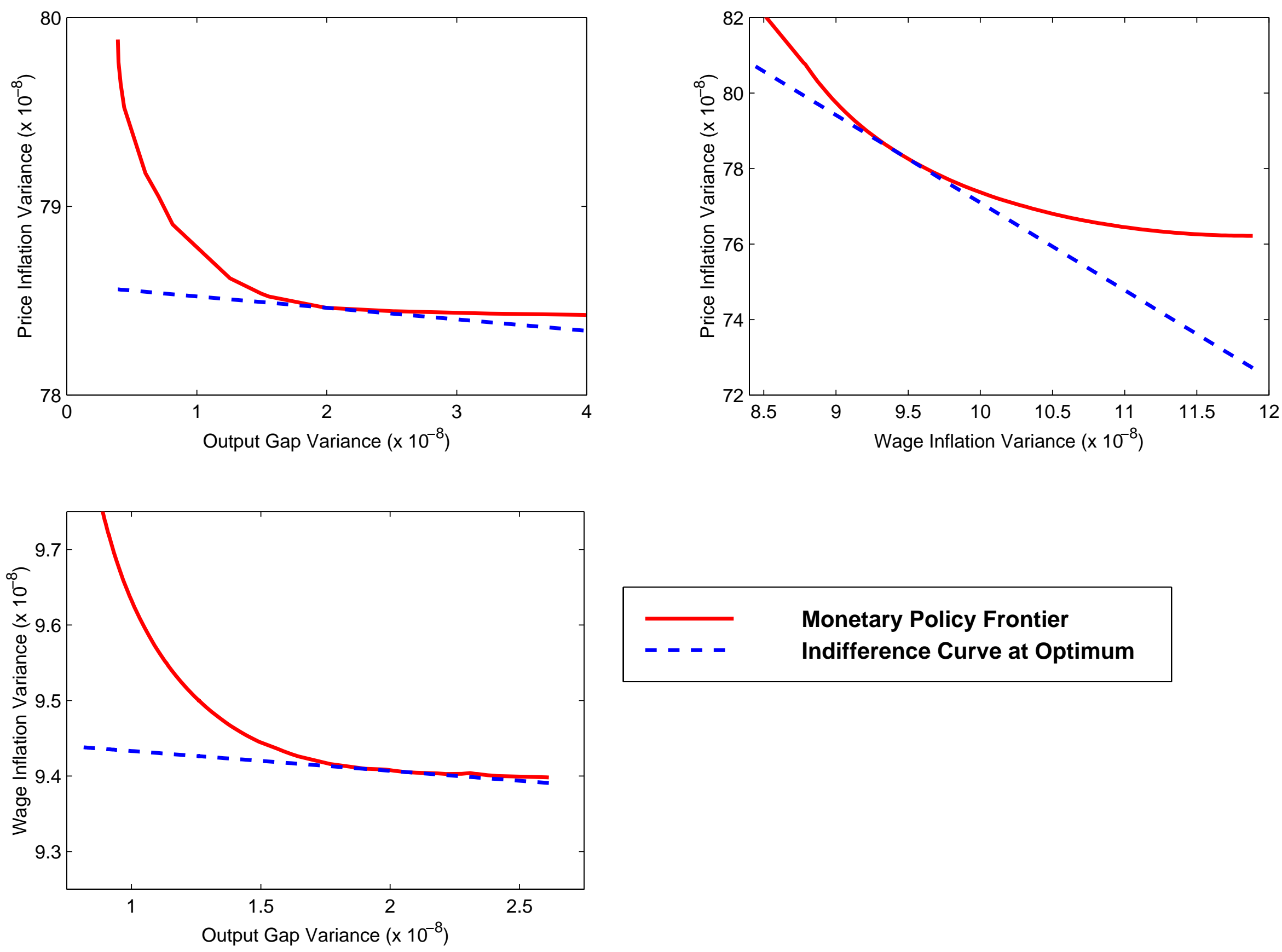


\section{Figure 3}

\section{Optimal Monetary Policy for Alternative Contract Durations}
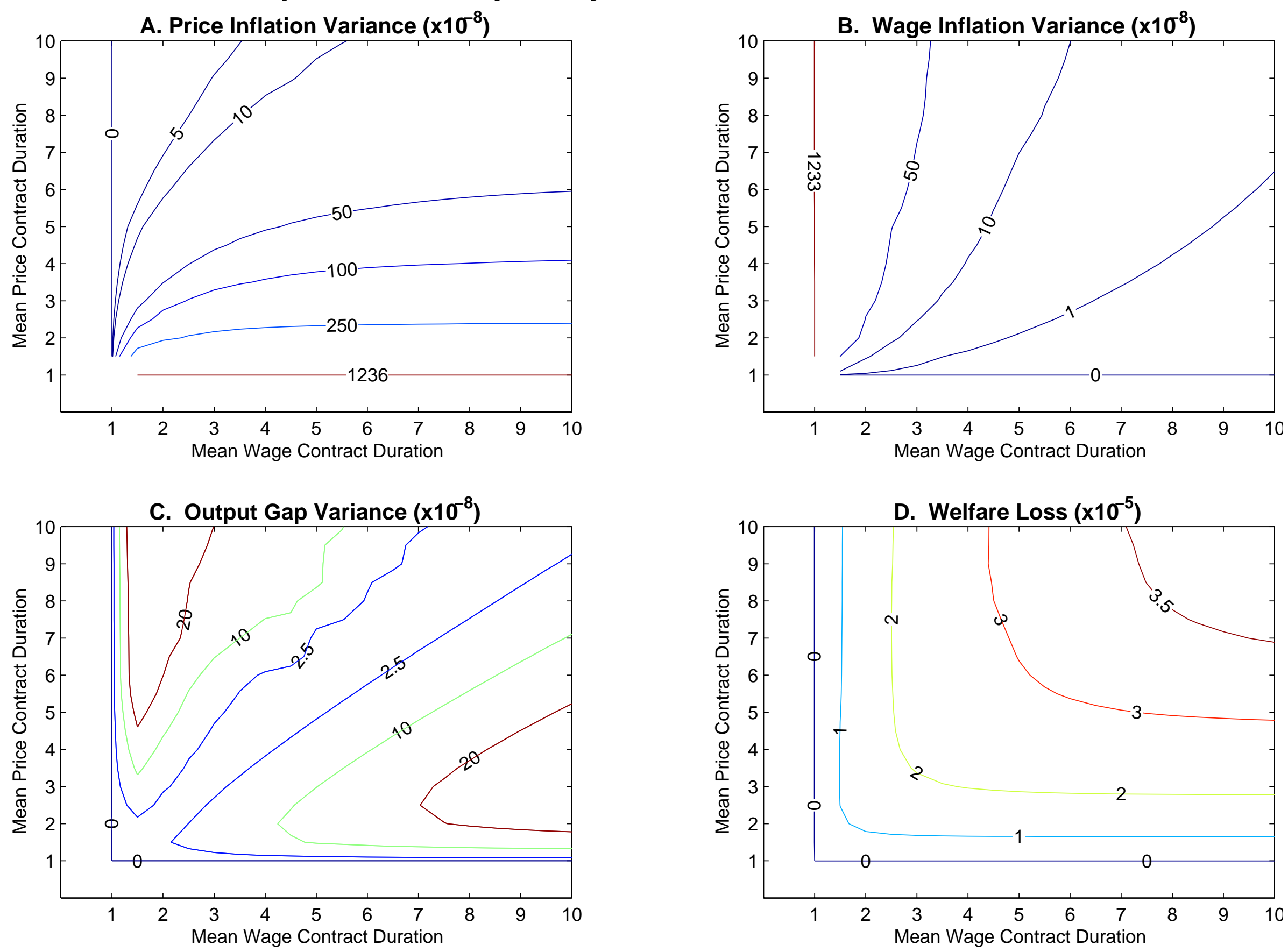


\section{Figure 4: Strict Price Inflation Targeting}

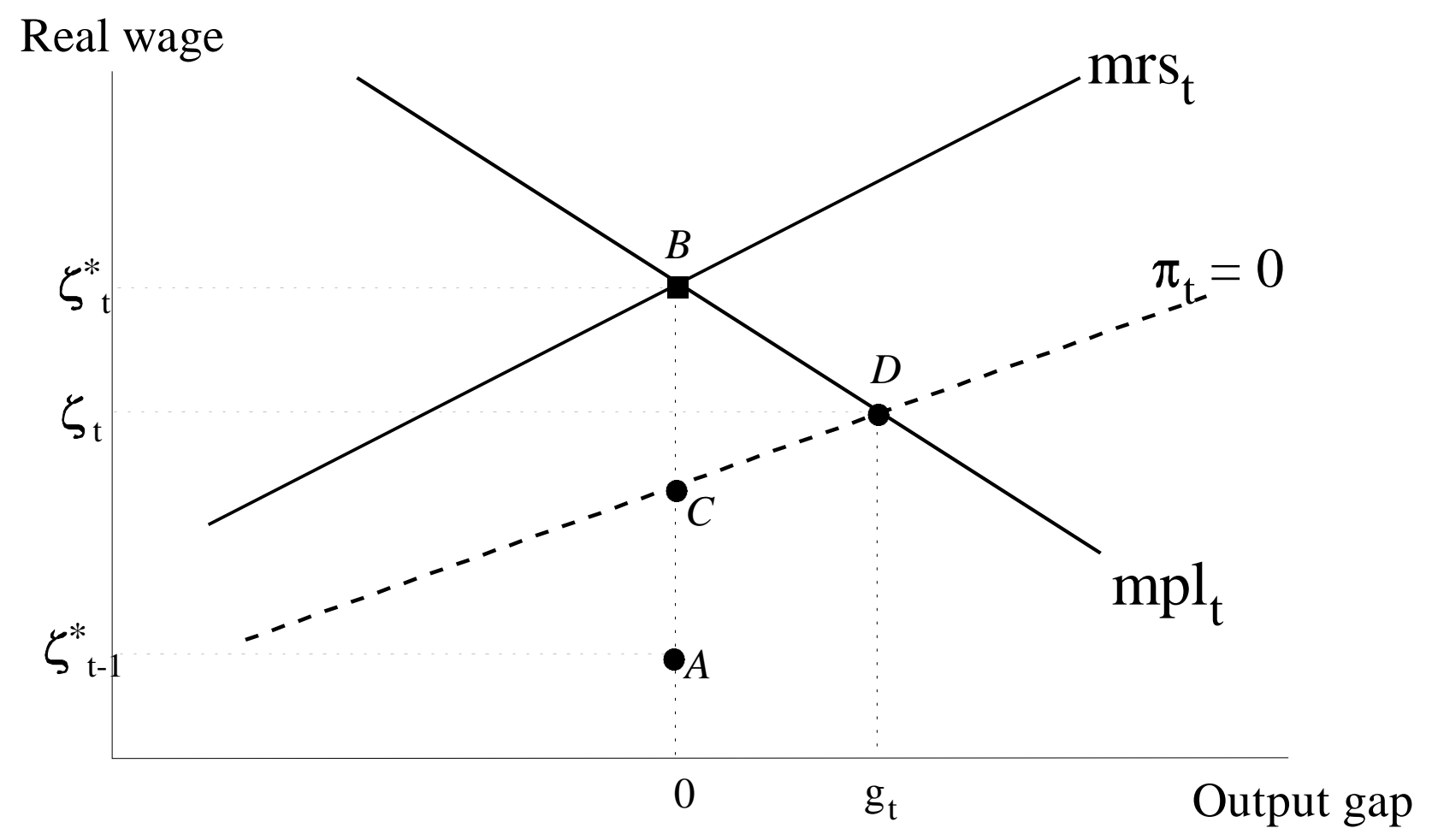

